\title{
Transforming Growth Factor $\alpha$ Transforms Astrocytes to a Growth-Supportive Phenotype after Spinal Cord Injury
}

\author{
Robin E. White, ${ }^{1,2}$ Meghan Rao, ${ }_{4}^{4}$ John C. Gensel, $, 2,3$ Dana M. McTigue, ${ }^{2,3}$ Brian K. Kaspar, ${ }^{2,4}$ and Lyn B. Jakeman ${ }^{1,2}$ \\ ${ }^{1}$ Department of Physiology and Cell Biology, ${ }^{2}$ Center for Brain and Spinal Cord Repair, and ${ }^{3}$ Department of Neuroscience, The Ohio State University, \\ Columbus, Ohio 43210, and 4The Research Institute at Nationwide Children's Hospital, Columbus, Ohio 43205
}

\begin{abstract}
Astrocytes are both detrimental and beneficial for repair and recovery after spinal cord injury (SCI). These dynamic cells are primary contributors to the growth-inhibitory glial scar, yet they are also neuroprotective and can form growth-supportive bridges on which axons traverse. We have shown that intrathecal administration of transforming growth factor $\alpha$ (TGF $\alpha$ ) to the contused mouse spinal cord can enhance astrocyte infiltration and axonal growth within the injury site, but the mechanisms of these effects are not well understood. The present studies demonstrate that the epidermal growth factor receptor (EGFR) is upregulated primarily by astrocytes and glial progenitors early after SCI. TGF $\alpha$ directly activates the EGFR on these cells in vitro, inducing their proliferation, migration, and transformation to a phenotype that supports robust neurite outgrowth. Overexpression of TGF $\alpha$ in vivo by intraparenchymal adenoassociated virus injection adjacent to the injury site enhances cell proliferation, alters astrocyte distribution, and facilitates increased axonal penetration at the rostral lesion border. To determine whether endogenous EGFR activation is required after injury, SCI was also performed on Velvet (C57BL/6J-Egfr $\left.{ }^{V e l} / \mathrm{J}\right)$ mice, a mutant strain with defective EGFR activity. The affected mice exhibited malformed glial borders, larger lesions, and impaired recovery of function, indicating that intrinsic EGFR activation is necessary for neuroprotection and normal glial scar formation after SCI. By further stimulating precursor proliferation and modifying glial activation to promote a growthpermissive environment, controlled stimulation of EGFR at the lesion border may be considered in the context of future strategies to enhance endogenous cellular repair after injury.
\end{abstract}

\section{Introduction}

Spinal cord injury (SCI) results in the permanent loss of motor, sensory, and autonomic function because the adult mammalian nervous system cannot regenerate. During development, astrocyte precursors support growing axons (Rakic, 1971; McDermott et al., 2005), and after SCI in lower vertebrates and very young mammals, astrocyte progenitors migrate from the ependymal zone to form a scaffold for regeneration (Chernoff et al., 2003; Fry et al., 2003; Rehermann et al., 2009). However, after SCI in adult mammals, astrocytes vacate the lesion core (Fitch et al., 1999) and form a cellular and molecular border at the lesion edge that is inhibitory to axon growth (Reier et al., 1983; Liuzzi and Lasek, 1987; Rudge and Silver, 1990). Peripheral axons grow within the lesion, but few centrally derived axons are able to extend beyond the glial border (Frisen et al., 1995; Houle and Jin, 2001; Inman and Steward, 2003; Camand et al., 2004). Even after removal of

Received July 6, 2011; revised Aug. 10, 2011; accepted Aug. 29, 2011.

Author contributions: R.E.W., M.R., B.K.K., and L.B.J. designed research; R.E.W., M.R., J.C.G., D.M.M., B.K.K., and L.B.J. performed research; B.K.K. contributed unpublished reagents/analytic tools; R.E.W., M.R., J.C.G., D.M.M., B.K.K., and L.B.J. analyzed data; and R.E.W., B.K.K., and L.B.J. wrote the paper.

This work was supported by Grants NINDS R01-NS043246 (L.B.J.), P30-NS045758 (D.M.M.), R01-NS066492 (B.K.K.) and the Ohio State University College of Medicine. We appreciate contributions from L. G. F. Smith, S. Holmes, F. Q. Yin, M. Hester, T. Lash, and Dr. E. Andrews. Confocal microscopy was performed at The Campus Microscopy and Imaging Facility, The Ohio State University.

The authors declare no competing financial interests.

Correspondence should be addressed to Dr. Lyn B. Jakeman, 403 Hamilton Hall, 1645 Neil Avenue, Columbus, $0 \mathrm{H}$ 43210. E-mail: Lyn.Jakeman@osumc.edu.

DOI:10.1523/JNEUROSCI.3441-11.2011

Copyright $\odot 2011$ the authors $\quad 0270-6474 / 11 / 3115173-15 \$ 15.00 / 0$ multiple inhibitory cues and profound stimulation of intrinsic growth potential, axonal growth is observed nearly exclusively in association with small remnants of astroglial bridges (Lee et al., 2010; Liu et al., 2010).

When it occurs, astrocyte migration can support growth of centrally derived axons even in adult mammals. Spontaneous astrocyte migration is accompanied by robust growth of central serotonergic fibers into the SCI lesion in 129X1/SvJ mice (Ma et al., 2004; White and Jakeman 2008). In addition, interventions that enhance astrocyte migration facilitate axon growth into cellular grafts or bridges (King et al., 2006; Deng et al., 2011). Accordingly, several researchers have transplanted astrocytes or astrocyte precursors into the site of SCI to encourage regeneration (Hasegawa et al., 2005; Davies et al., 2006; Filous et al., 2010; Jin et al., 2011). However, with increasing evidence of glial heterogeneity and plasticity (Davies et al., 2008; Meletis et al., 2008; White et al., 2010; Remboutsika et al., 2011), we propose that an attractive alternative strategy is to target the endogenous astrocyte response and stimulate the formation of growth-permissive cellular bridges to support growing axons.

We have shown previously that intrathecal infusion of transforming growth factor $\alpha$ (TGF $\alpha$ ) can alter the glial border and enhance axonal growth after spinal contusion (White et al., 2008). However, TGF $\alpha$ acts on the epidermal growth factor receptor (EGFR) found on many different cell types, and the site of action of these effects was not clear. The present studies demonstrate that early after SCI, the EGFR is upregulated primarily by astrocytes and astrocyte precursors surrounding the lesion. 
TGF $\alpha$ acts directly on these cells in vitro to stimulate proliferation, migration, and transformation to an axon growth-supportive phenotype. Intraparenchymal overexpression of TGF $\alpha$ at the border adjacent to an SCI enhances proliferation and reduces the astrocyte-free core, allowing extension of more axons at the rostral lesion border. A loss-of-function mutant shows that the endogenous EGFR response is neuroprotective. Thus, despite recent studies demonstrating potential benefits of EGFR inhibition, the present results reveal that EGFR activation has positive effects on the endogenous cellular response after SCI.

\section{Materials and Methods}

\section{Mice and spinal cord injury}

Adult female C57BL/6 mice (17-21 g) were obtained from The Jackson Laboratory or Charles River Laboratories and housed in barrier cages in a temperature- and humidity-controlled room with ad libitum access to food and water. Mice lacking functional EGFRs (C57BL/6J-Egfr $\left.{ }^{V e l} / \mathrm{J}\right)$ were obtained from The Jackson Laboratory (stock \#006926). The Velvet mutation is a dominant substitution of adenine-to-guanine, leading to an amino acid change from aspartic acid to glycine at position 833 of the protein (D833G). This results in loss of ATP coupling and subsequent EGFR signaling (Du et al., 2004). Mutant animals were backcrossed to C57BL/6J at The Jackson Laboratory for at least 10 generations. Heterozygous affected mice were maintained for six to seven generations in house by mating heterozygous males (Velvet) with wild-type (WT) females. Affected progeny are viable and fertile with no behavioral abnormalities. They exhibit open eyelids at birth and a first coat of wavy hair allowing visible determination of genotype (Du et al., 2004). All animal experimentation procedures followed institutionally approved protocols in accordance with the NIH Guide to the Care and Use of Laboratory Animals.

Mice were anesthetized with ketamine $(80 \mathrm{mg} / \mathrm{kg}$; Vedco) and xylazine (10 mg/kg, i.p.; Ben Venue Laboratories), and a thoracic vertebral level 9 (T9) laminectomy was performed under aseptic conditions. Moderate contusion injury was produced using the Ohio State University Electromagnetic Spinal Cord Injury Device (ESCID; $0.5 \mathrm{~mm}$ ) (Jakeman et al., 2000; expression studies and Experiments 1 and 2) or the Infinite Horizons Injury Device (IH device; 75 kdyn; Scheff et al., 2003) (Experiment 3 and Velvet; see groups below). Both injury devices impart a controlled contusion to the exposed intact dura after a T9 laminectomy and yielded a force range of $75-110 \mathrm{kDyn}$ and maximal displacement of $0.49-0.83$ $\mathrm{mm}$ over a $10-25 \mathrm{~ms}$ period. After injury, the overlying muscles were sutured with 4-0 silk, the skin openings were closed with vicryl, and the mice were allowed to recover in warmed cages overnight. Bladders were expressed twice daily for the duration of the experiments. All mice had access to laboratory chow, peanut butter, and sweetened cereal to minimize weight loss after injury. Subcutaneous injections of Gentamicin (5 $\mathrm{mg} / \mathrm{kg}$; Vedco) and $0.9 \%$ saline ( $1-3 \mathrm{cc}$ ) were administered for $5 \mathrm{~d}$ after injury.

\section{Expression and distribution of EGFR after SCI}

Western blotting. Naive and injured mice at 4,7 , or $15 \mathrm{~d}$ postinjury (DPI) $(n=4$ per group) were anesthetized with ketamine $(120 \mathrm{mg} / \mathrm{kg})$ and xylazine $(15 \mathrm{mg} / \mathrm{kg})$ and perfused with sterile $0.9 \%$ saline. A $4 \mathrm{~mm}$ block of tissue centered on the injury or control spinal level was removed and homogenized in EDTA buffer containing protease and phosphatase inhibitors (Pierce T-PER and Halt Solutions; Thermo Fisher Scientific). After centrifugation, $15 \mu \mathrm{g}$ of protein from each unpooled tissue supernatant was denatured and separated on a $10 \%$ polyacrylamide gel under reducing conditions. The protein was transferred to Immobilon PVDF membrane (Sigma) and blocked in 5\% nonfat milk in TBS with $0.1 \%$ Tween 20 (Sigma). The membranes were incubated overnight in rabbit anti-EGFR (1:200, sc-1005; Santa Cruz Biotechnology) or rabbit anti- $\beta$ tubulin (1:400; Sigma) followed by $2 \mathrm{~h}$ in HRP-labeled goat anti-rabbit IgG (1:4000, Jackson Immunoresearch Laboratories). Blots were developed with ECL reagent (Pierce), and signal was detected on BX film (MidSci). The films were scanned, and the integrated optical density (IOD) of each target band was quantified and expressed as EGFR/ $\beta$ - tubulin using Gel-Pro Analyzer software (version 3.1; Media Cybernetics). IOD ratios were normalized to the control (naive) tissue values and compared by one-way ANOVA followed by Tukey's multiple comparison test using Prism 5.0 software (GraphPad Software).

EGFR immunohistochemistry. Mice received moderate T9 contusive spinal cord injury with the ESCID as above. Naive mice and mice at 3 or 7 DPI were anesthetized and perfused with $0.1 \mathrm{M}$ PBS and $4 \%$ paraformaldehyde (PFA) in $0.1 \mathrm{M}$ PBS. Brains and spinal cords were postfixed for $2 \mathrm{~h}$ and cryoprotected in $30 \%$ sucrose. Spinal cord blocks of $0.8 \mathrm{~cm}$ length were centered on the laminectomy site, and serial transverse sections were collected at $10 \mu \mathrm{m}$ thickness in 10 sets of sections, each spaced 100 $\mu \mathrm{m}$ apart. Adjacent sets of sections were dual labeled with antibodies against EGFR [sheep anti-EGFR, 1:1000 (Abcam) or 1:400 (Lifespan Biosciences)] and cell markers, including glial fibrillary acidic protein (GFAP; rabbit anti-bovine, 1:5000; Dako), neurofilament (NF; chicken anti-200 kDa NF, 1:200; Aves Laboratories), or brain lipid binding protein (rabbit anti-BLBP, 1:1000; Millipore) to identify mature astrocytes, axons, or astrocyte lineage cells, respectively (White et al., 2010). Sections were blocked with $5 \%$ bovine serum albumin (Sigma), $1 \%$ fish gelatin (Sigma), and $0.1 \%$ Triton X-100 (Sigma) in PBS and incubated in primary antibodies overnight at $4^{\circ} \mathrm{C}$ and in fluorescent-labeled secondary antibodies for $2 \mathrm{~h}$ at room temperature (Alexafluor, 1:200; Invitrogen). Slides were coverslipped with Immumount (Thermo Fisher Scientific). Controls for staining specificity and cross-reactivity for each antibody were performed using normal serum in place of each primary antibody as described previously (White et al., 2010).

\section{In vitro studies}

Adult spinal cord neural progenitor cell and neural progenitor cell-derived astrocytes. Adult spinal cord neural progenitor cells (ASCNPCs) were isolated from 8- to 12 -week-old C57BL/6 mice as described previously (Ray and Gage, 2006) and used from passages 17-21. To prepare astrocytes, ASCNPCs were seeded on a $10 \mathrm{~cm}$ plate coated with poly-Lornithine (10 $\mu \mathrm{g} / \mathrm{ml}$; Sigma) and EHS-laminin ( $5 \mu \mathrm{g} / \mathrm{ml}$; Invitrogen) in mouse neural stem cell expansion medium (MNSCEM; serum-free N2 medium composed of DMEM/F-12, 1 mM L-glutamine, $1 \times$ PSF (antibiotic-antimycotic; Invitrogen), and $1 \times \mathrm{N} 2$ supplement and containing 20 $\mathrm{ng} / \mathrm{ml} \mathrm{FGF-2,} 20 \mathrm{ng} / \mathrm{ml} \mathrm{EGF}$, and $5 \mu \mathrm{g} / \mathrm{ml}$ heparin; Ray and Gage, 2006) until they were at least $80 \%$ confluent. Cells were then rinsed with sterile PBS (Invitrogen), and the medium was replaced with MNSCEM containing 10\% fetal bovine serum (FBS; Invitrogen) (Brunet et al., 2004). Cells were maintained in FBS medium for $7 \mathrm{~d}$, with the medium changed every $2 \mathrm{~d}$. At this stage, the cultures were enriched in astrocytes but also contained undifferentiated precursors. These cultures were thus called "mixed astrocyte cultures" and were used in migration assays because they model a mixed population of astrocyte lineage cells present in the injured spinal cord after trauma (Meletis et al., 2008; White et al., 2010). To obtain more purified and fully differentiated astrocyte cultures, the medium was next replaced with MNSCEM plus 10\% FBS with $20 \mu \mathrm{M}$ cytosine arabinoside (Sigma) for $2 \mathrm{~d}$ to abolish proliferating cells. This was followed by an additional $2 \mathrm{~d}$ in MNSCEM plus $10 \%$ FBS, yielding a 97\% GFAP-positive population.

$T G F \alpha$ treatment in vitro. Cells prepared as above were plated on glass coverslips coated with laminin $(50 \mu \mathrm{g} / \mathrm{ml})$ and poly-ornithine $(5 \mu \mathrm{g} / \mathrm{ml})$. Human recombinant TGF $\alpha$ (R\&D Systems) was added to serum-free, growth factor-free medium at $0-100 \mathrm{ng} / \mathrm{ml}$. Unless stated otherwise, 10 $\mathrm{ng} / \mathrm{ml}$ TGF $\alpha$ was added to fresh medium daily for $3 \mathrm{~d}$ for ASCNPCs and $25 \mathrm{ng} / \mathrm{ml}$ TGF $\alpha$ was added for $5 \mathrm{~d}$ for astrocytes. In control wells, the EGFR inhibitor AG1478 (Calbiochem; $10 \mu \mathrm{M}$ final concentration) was added to the medium 30 min before TGF $\alpha$ (as per the manufacturer's instructions).

Proliferation (bromodeoxyuridine incorporation). ASCNPCs or astrocytes were plated on glass coverslips in 12-well (ASCNPCs) or 24-well (astrocytes) plates at a density of 200,000 cells per well. TGF $\alpha$ was added at $0-100 \mathrm{ng} / \mathrm{ml}$ in MNSCEM. Six hours before fixation, a single dose of $10 \mu \mathrm{m}$ bromodeoxyuridine (BrdU; Sigma) was added to each well. Cells were fixed with $4 \%$ PFA for $20 \mathrm{~min}$ and stained with rat anti-BrdU (1:400; Accurate Chemical and Scientific Corporation), followed by FITC- or Cy-5 labeled goat anti-rabbit secondary antibody (1:125; Jack- 
son Immunoresearch Laboratories) in the presence of 4',6-diamidino-2phenylindole (DAPI; 1:250; Invitrogen) to identify cell nuclei. Coverslips were then placed on glass slides with polyvinyl alcohol mounting medium with 1,4-diazabicyclo[2.2.2] octane (Sigma). To count BrdU+containing cells, five nonoverlapping images from the top, right, bottom, and left quadrants and center of each coverslip ( $n=3$ per group) were collected with the Axioplan microscope (Zeiss) at $20 \times$ magnification (Sharif et al., 2006). Each counting field had an area of $27 \mathrm{~mm}^{2}$, and each coverslip had an area of $380 \mathrm{~mm}^{2}$, for a total sampling area of $35 \%$. Images were saved as TIFF files, and the numbers of BrdU+ cells and DAPI + cells per field were determined with particle counting methods using the MCID image analysis program (InterFocus Imaging Ltd.). Average cell nucleus size was set at $82 \mu \mathrm{m}^{2}$, based on a sample of $30-40$ $\mathrm{BrdU}+$ cells. Intensity levels were set to saturate the labeled cells without including background staining. Data are presented as either the number of BrdU + cells per square millimeter or the percentage of total cells that were BrdU+ (number of BrdU+ cells/number of DAPI+ cells).

Wound closure (migration). ASCNPCs, mixed cultures, or astrocytes were plated at a density of 180,000 cells/well (confluent soon after plating) on poly-ornithine- and laminin-coated glass coverslips in 24-well plates (coverslip area, $95 \mathrm{~mm}^{2}$ ). After $24 \mathrm{~h}$, a linear scratch was made in the cell layer using a sterile plastic pipette tip, and the cells were maintained in the treatment medium for $1-5 \mathrm{~d}$. Phase-contrast images centered on the scratch in three wells per treatment were collected daily to track the progression of migration over time (Faber-Elman et al., 1996). After $3 \mathrm{~d}$ (ASCNPCs) or $5 \mathrm{~d}$ (astrocytes), the cells were fixed with $4 \%$ PFA and immunolabeled with anti-nestin (chicken anti-Nestin, 1:200; Aves Laboratories) or anti-GFAP (guinea pig anti-GFAP, 1:1000; Advanced Immunochemical) antibodies. Final images of stained cultures centered on the scratch wound $(20 \times)$ were collected on an inverted confocal or 510 META confocal microscope (Zeiss). The phase-contrast images were analyzed by measuring the proportional area inhabited by cells within the scratch region based on edge detection using the MCID image analysis program. Confocal images of nestin and GFAP immunoreactivity were analyzed by outlining the principle edge of the wound based on the saved phase-contrast images and thresholding and measuring the percentage of the scratch area occupied by nestin + or GFAP+ staining using NIH ImageJ software (by W. Rasband, available at http://rsbweb.nih.gov/).

Transformation and changes in morphology. ASCNPCs or astrocytes were plated at a density of 180,000 cells/well and exposed to TGF $\alpha$ or vehicle. After $0-5 \mathrm{~d}$, cells were fixed with $4 \%$ PFA; stained with antiGFAP, rabbit anti- $\beta$ III tubulin (1:2000; Sigma), rabbit anti-BLBP (1: 1000; Millipore), or rabbit anti-NG2 (1:100, US Biological); and counterstained with DAPI. Images of five regions per well were captured at $20 \times$ magnification on the Axioplan microscope (Zeiss) with a $10 \times$ eyepiece. To compare expression levels across wells, images were collected under identical lighting conditions, and the mean relative intensity of each image was measured using the densitometric analysis feature of the MCID.

Dorsal root ganglion axonal growth assay. Confluent ASCNPC or astrocyte cultures were prepared in 24-well plates and treated with control medium or TGF $\alpha$ for $3-5 \mathrm{~d}$; the medium was then removed, and the cells were rinsed twice with sterile PBS. Dorsal root ganglion (DRG) cells were isolated from adult C57BL/6 mice using previously described methods (Gensel et al., 2009). The DRG cells were plated on the confluent cultures at a density of 1600 DRG cells/well in Neurobasal A medium (Sigma). An additional group of DRGs was plated directly on glass coverslips coated with poly-D-lysine $(25 \mu \mathrm{g} / \mathrm{ml})$ and laminin $(10 \mu \mathrm{g} / \mathrm{ml})$ with or without 10 $\mathrm{ng} / \mathrm{ml} \mathrm{TGF} \alpha$. After $24 \mathrm{~h}$, the cocultures were fixed with $2 \%$ PFA, stained with rabbit anti- $\beta$ III tubulin (1:2000; Sigma) or chicken anti-NF (1: 3000; Aves Laboratories), and, in some cases, counterstained with rabbit or mouse anti-GFAP, followed by the appropriate Alexafluor secondary antibodies (Invitrogen). Neurite outgrowth was measured using methods described by Gensel et al. $(2009,2010)$. Randomly placed $10 \times$ images of stained DRGs were taken with an Axioplan microscope (Zeiss) with an automated stage set to photograph $\sim 45 \%$ of the coverslip. TIFF images were collected, and cells were counted if there was an intact cell body in the image and if neurites did not contact other neurites. An automated Sholl analysis (Gensel et al., 2010) was used to determine maximum neurite outgrowth length. Approximately $30-150$ cells were measured per treatment group.

\section{TGF $\alpha$ adeno-associated virus overexpression in vivo}

Preparation of $T G F \alpha$, green fluorescent protein, and empty adenoassociated virus vectors. TGF $\alpha$ expression was upregulated by endogenous cells in the parenchyma of the spinal cord after microinjection of an adeno-associated virus (AAV) serotype 1. To prepare the TGF $\alpha$-AAV, human TGF $\alpha$ cDNA (Open Biosystems) was cloned into an AAV plasmid under a cytomegalovirus promoter. Verification of TGF $\alpha$ production was performed by transfecting human embryonic kidney 293 (HEK293) cells (Stratagene), collecting the supernatant $24 \mathrm{~h}$ later, and performing a Quantikine ELISA for human TGF $\alpha$ (R\&D Systems). The plasmid was sent to Marion Scientific for construction of virus at a titer $10^{9}$ viral genome copies per microliter, and production of TGF $\alpha$ by the final AAV was confirmed in HEK293 cells by ELISA.

An AAV (serotype 1) expressing enhanced GFP-AAV was used to identify the distribution and cell types of viral incorporation after microinjection into the parenchyma of the intact spinal cord. The GFP-AAV was produced in house by transient triple transfection of (1) a recombinant AAV plasmid carrying the GFP, (2) the AAV helper plasmid pAAV/Ad encoding Rep2 and Cap, and (3) a plasmid carrying adenoviral helper functions into HEK293 cells using calcium phosphate precipitation. After $72 \mathrm{~h}$, the AAV was harvested and purified by density gradient centrifugation to yield a typical titer of $1 \times 10^{12}$ viral genome copies $/ \mu$ l. Genome titer was measured by quantitative PCR using the iCycler (BioRad) (Kota et al., 2009). Finally, for control subjects in Experiment 3 below, an empty AAV of serotype 1 (eAAV) was produced in house using similar methods but lacking the TGF $\alpha$ or GFP transcript.

In vivo injections of $A A V$. To administer the viruses in vivo, a midthoracic (T9) laminectomy was performed on adult mice as described above, and injections of the TGF $\alpha$-AAV (Experiments 1-3), GFP-AAV (Experiment 1), PBS (Experiment 2), or eAAV (Experiment 3) were made at both the rostral and caudal ends of the laminectomy site using pulled glass micropipettes. Pipettes (tip diameter, $40-60 \mu \mathrm{m}$ ) were coated in sterile saline, loaded with $\sim 20 \mu \mathrm{l}$ of solution, placed in a hydraulic micromanipulator, and attached to a PV800 Pneumatic Pico Pump (World Precision Instruments). At each site, the pipette was lowered $800 \mu \mathrm{m}$ beneath the dorsal surface of the spinal cord, and $2 \mu \mathrm{l}$ of AAV was injected at a rate of $1 \mu \mathrm{l}$ per $15 \mathrm{~min}$. After injection, the pipette was slowly raised, a small square of DuraFilm (American Durafilm) was placed over the laminectomy site, and the muscle layers were sutured. In all studies, the mice were monitored for 2 weeks after injection to allow viral replication and incorporation and expression of the transgene. Locomotor testing was performed at $2 \mathrm{~d}$ after injection to ensure no detectable functional damage was caused by the procedure.

Verification of TGF $\alpha$ expression in vivo. TGF $\alpha$ gene expression was confirmed by RT-PCR and ELISA. For RT-PCR, mice were reanesthetized 2 or 8 weeks ( $n=4$ per group) after injection, and a $4 \mathrm{~mm}$ section of spinal cord centered at the laminectomy site was rapidly removed and placed immediately into TRIzol reagent (Invitrogen). The tissue was homogenized and frozen at $-80^{\circ} \mathrm{C}$, and RNA was isolated as described previously (Kigerl et al., 2007). For a positive control, HEK293 cells were transfected with the TGF $\alpha$ viral plasmid, and RNA was isolated $24 \mathrm{~h}$ later using the RNeasy Mini kit (QIAGEN). The First Strand Superscript RT System (Invitrogen) was used to synthesize cDNA from RNA. PCR was then performed using primers specific to human TGF $\alpha$ (Invitrogen; forward primer, TGACGTCAATGGGTGGAGTA; reverse primer, GACCTGGCAGCAGTGTATCA). The following program was used: 40 cycles of $94^{\circ}$ for $15 \mathrm{~s}, 60^{\circ}$ for $30 \mathrm{~s}$, and $72^{\circ}$ for $30 \mathrm{~s}$.

To confirm production of TGF $\alpha$ peptide, additional tissues were prepared for ELISA from spinal cords of naive mice or mice that had received TGF $\alpha$-AAV or eAAV and were perfused 2 weeks later, or mice that had received SCI only with the $\mathrm{IH}$ device and were perfused $10 \mathrm{~d}$ later $(n=3$ per group). The mice were anesthetized and perfused with cold saline, and a $4 \mathrm{~mm}$ block of spinal cord centered at the laminectomy site was removed and flash frozen in liquid nitrogen. Samples were then thawed in protein lysis buffer (10 mM HEPES, $42 \mathrm{~mm} \mathrm{KCl,} 5 \mathrm{~mm} \mathrm{MgCl}_{2}, 0.1 \mathrm{~mm}$ ETDA, 0.1 mM EGTA, and 0.1\% Triton X-100) with protease inhibitor, 
and the mixture was sonicated for $5 \mathrm{~s}$. The tissue was then centrifuged at $13,000 \mathrm{rpm}$ for $60 \mathrm{~min}$, and the supernatant was collected as the cytoplasmic fraction. Protein concentrations were determined by the bicinchoninic acid method (BCA Protein Assay kit; Pierce). Eighty-five micrograms of protein were diluted in $50 \mu \mathrm{l}$ of the TGF $\alpha$ ELISA diluent. Samples were run in duplicate and fit onto a standard curve generated from the manufacturer's reagents. Values were adjusted to reflect picograms of TGF $\alpha$ present in each sample.

Distribution of AAV infection with GFP-AAV. Four intact mice that had received GFP-AAV only were perfused 2 weeks after microinjections, and tissues were processed for immunohistochemistry. No behavioral deficits were observed at any time after the injection. Infection of neurons and astrocytes with GFP was verified by double labeling with GFAP and NeuN (mouse anti-NeuN, 1:500, Millipore), respectively.

Overexpression of TGF $\alpha$ after contusive SCI. In the first study (Experiment 1 ), mice received either GFP-AAV or TGF $\alpha$-AAV ( $n=3$ per group) as described in the paragraph above. These mice were then allowed to recover for 2 weeks, the laminectomy site was reexposed, and the mice were subjected to a moderate contusion injury using the ESCID device. They were perfused $10 \mathrm{~d}$ later, and the tissues were sectioned in the longitudinal plane to examine the lesion border. Anecdotally, we later used the GFP-AAV approach as a control for a longer-term study; some mice were allowed to survive for 8 weeks after injury, but these tissues revealed an unexpected confound in which prolonged administration of the GFP-AAV was associated with distinct regions of white matter demyelination that colocalized with high GFP expression in tissue sections (data not shown). Therefore, the GFP-AAV was ruled out as a control reagent. In the second experiment described here (Experiment 2), two groups of mice received TGF $\alpha$-AAV or an equal volume of PBS $(n=6$ per group) and were allowed 2 weeks for upregulation of the transgene, were subjected to moderate contusion injury with the ESCID device, and were tested for locomotor activity [Basso Mouse Scale (BMS)] at 3, 7, and $10 \mathrm{DPI}$ and at $10 \mathrm{DPI}$, and the tissues were sectioned in the transverse plane for full three-dimensional histological analysis. To confirm that the observed effects on the cellular response to injury could be directly attributed to expression of TGF $\alpha$, a third experiment (Experiment 3) was performed where mice received either TGF $\alpha$-AAV or an empty AAV of the same serotype ( $n=4$ per group for histology; $n=3$ per group for ELISA). These mice were subjected to moderate contusion injury, with the $\mathrm{IH}$ device at a force $(75 \mathrm{kDa})$ that produces a lesion and behavioral outcomes that closely match the moderate ESCID injury, and perfused $10 \mathrm{~d}$ later. One eAAV specimen died $2 \mathrm{~d}$ after injury, and one TGF $\alpha$-AAV tissue block was damaged, leaving $n=3$ for each group. The final GFAP and NF values from the two TGF $\alpha$-AAV treatment groups in Experiments $2(n=6)$ and $3(n=3)$ were overlapping, and these groups were combined.

\section{Histological analysis of effects of TGF $\alpha$ on the lesion site}

Identification of the lesion epicenter and lesion volumes. Ten adjacent sets of transverse sections at $100 \mu \mathrm{m}$ spacing were used for quantitative histological analysis as described previously. One set was stained with Eriochrome cyanine (EC) and cresyl violet (CV), and the lesion epicenter was defined as the region with the smallest area of white matter sparing (White et al., 2008). To determine lesion and spared tissue volumes, stained sections at $200 \mu \mathrm{m}$ intervals spanning the epicenter were photographed at low power. The regions of interest were defined by stain intensity and color and outlined on printed images, and the Cavalieri point-counting method was used to estimate the area and volumes using standard methods (White et al., 2008, 2010; Jakeman 2011).

GFAP, NF, laminin, and BrdU quantification. The distribution of astrocytes, axons, and basal lamina was examined using antibodies against GFAP (rabbit polyclonal anti-GFAP, 1:1000; Dako), NF-200 kDa (chicken anti-NF-200, 1:200; Aves Laboratories), and $\gamma$-laminin (rat anti-laminin B2, 1:2000; Millipore), respectively. Images including the full lesion were obtained from equally spaced sections at $200 \mu \mathrm{m}$ intervals from $1.4 \mathrm{~mm}$ rostral to $1.4 \mathrm{~mm}$ caudal from the lesion epicenter, resulting in 15 sections per animal spanning a rostrocaudal length of 3.0 $\mathrm{mm}$. The area per section in square millimeters and volume of the GFAPfree region was estimated from the images using the Cavalieri point- count method (Howard and Reed, 1998), and the area density of stained axons and laminin (proportional area $=$ target area/reference lesion area) were determined using calibrated MCID computer-generated pixel counts, where the lesion borders were outlined on the images based on spared gray and white matter histology in the EC/CV-stained section series for each section. This approach allows visualization of the rostrocaudal distribution, which reflects an estimate of the volume fraction $(\mathrm{Vv})$ of NF and laminin staining as a function of the lesion volume. To illustrate additional qualitative characteristics of some of the axons present in the lesion of TGF $\alpha$-AAV-treated mice, additional selected sections were labeled with specific antibodies against GAP43 (rabbit anti-GAP43, 1:4000; Millipore), a marker of growing or regenerating axons (Skene and Willard, 1981), and 5-HT (goat anti-5-HT, 1:5000; ImmunoStar), a marker of descending centrally derived serotonergic fibers.

The extent and distribution of early cell proliferation at the lesion border was determined after a single intraperitoneal injection of 50 $\mu \mathrm{g} / \mathrm{ml}$ BrdU given at 3 DPI (White et al., 2010). One set of $10-\mu \mathrm{m}$-thick tissue sections spaced $100 \mu \mathrm{m}$ apart was triple stained with rat anti-BrdU, rabbit anti-BLBP, and chicken anti-NF-200 antibodies. Images of BLBP staining were obtained from sections at $200 \mu \mathrm{m}$ intervals spanning the lesion epicenter, and these were used to map the astrocyte border. Two sections spanning the rostral pole of the lesion and two sections spanning the caudal pole were identified. These sections and the intervening section (total of three sections at $100 \mu \mathrm{m}$ intervals for each pole) were selected, and images of BrdU staining were captured with the MCID Acquisition software and $20 \times$ objective. The BrdU + nuclei were larger in diameter than the section thickness, so the optical fractionator method was not feasible for absolute cell counts (Williams and Rakic, 1988). To estimate the relative numbers of labeled nuclei at the lesion borders, a sample box of $200,000 \mu \mathrm{m}^{2}$ was centered on the rostral and the caudal lesion poles, and the digitized image was subjected to a counting paradigm such that objects were identified as BrdU+ nuclei if they had sufficient intensity to indicate positive stain, and if they were $>15 \mu \mathrm{m}^{2}$ and $<125 \mu \mathrm{m}^{2}$ in area. Counts from the three adjacent sections per animal were averaged to provide an estimate of nuclei per section for the rostral and caudal borders. This and all histological analyses were done using slides coded by an independent participant to ensure the investigator had no knowledge of the treatment group during image collection or data analysis.

\section{Behavioral recovery after contusion}

Behavioral recovery was evaluated after contusion injury using the Basso Mouse Scale (Basso et al., 2006). Mice were observed by a team of two trained testers blind to treatment group and were assigned a score of $0-9$ based on operationally defined criteria with regard to use of the hindlimbs in forward locomotion. Mice that received injections of AAV or PBS were tested on 1 and 10 DPI. Testing was done on Velvet mice 1, 3 , and 7 DPI and weekly thereafter until the time of perfusion at 28 DPI. To determine whether differences in BMS scores for Velvet mice were caused by changes in general locomotor activity after injury, the Velvet and WT mice were also evaluated in an open-field activity box paradigm (Open Field and Fusion software; AccuScan Instruments). The mice were placed into $8 \times 8$ inch chambers of the activity box during the same hours of the day as BMS testing was performed, and the software configured to collect data on total movement time and total distance in $10 \mathrm{~min}$ increments.

\section{Statistical analyses}

In vitro assays were analyzed across treatment groups with Student's $t$ tests (proliferation, neurite outgrowth on astrocytes) or either one-way or two-way ANOVA followed by Bonferroni post hoc tests when treatment effects were significant. The $\chi^{2}$ analysis was used to determine differences in the percentage of DRGs exhibiting neurites. The in vitro assays were replicated two to three times. For proliferation assays, sample sizes (numbers of wells per condition) were determined using $\mathrm{G}^{\star}$ Power 3 based on pilot studies (Erdfelder et al., 1996). One-way ANOVA was used to assess effects of treatment group for ELISA and lesion volume data with post hoc comparisons across groups using Bonferroni-corrected $t$ tests if main effects were significant. Anatomical analyses across the le- 

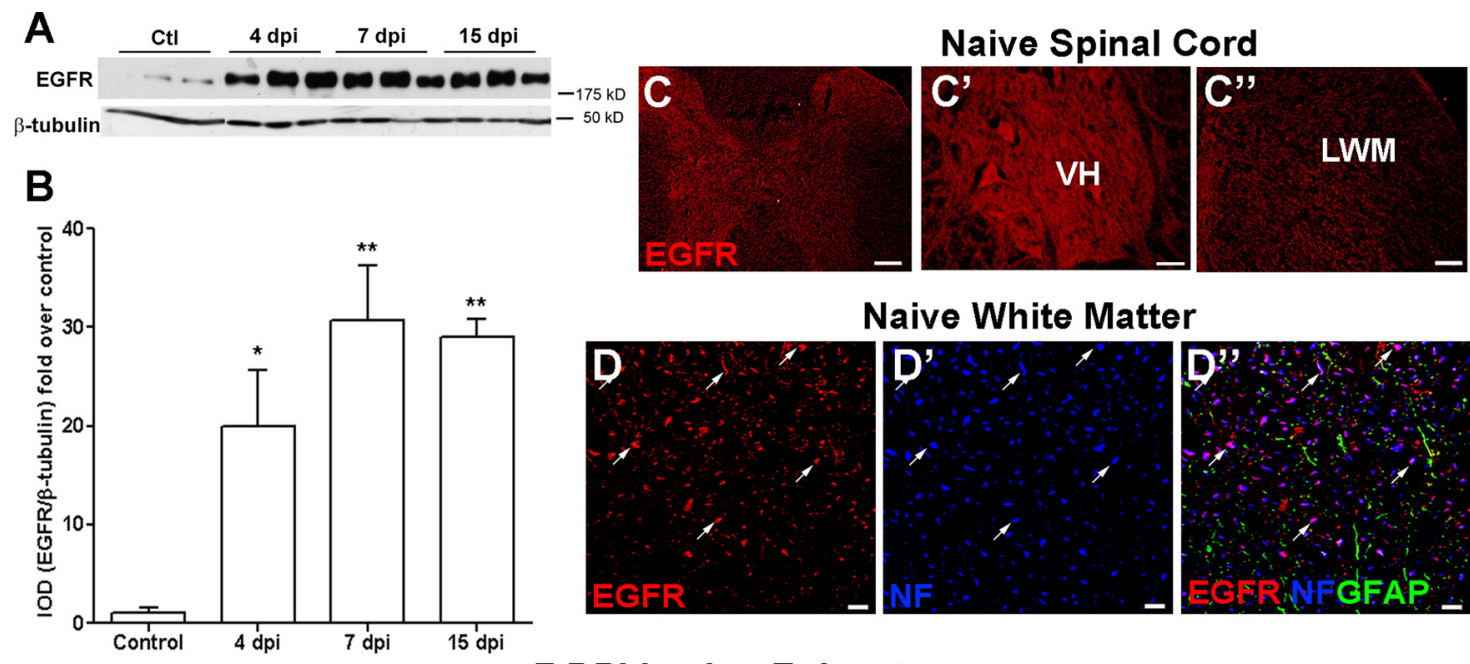

Naive White Matter

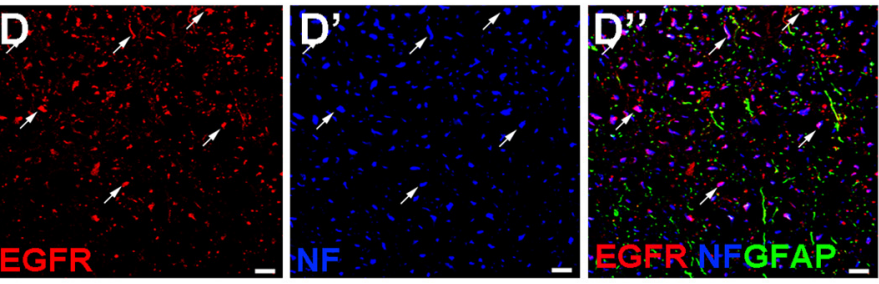

7 DPI Lesion Epicenter

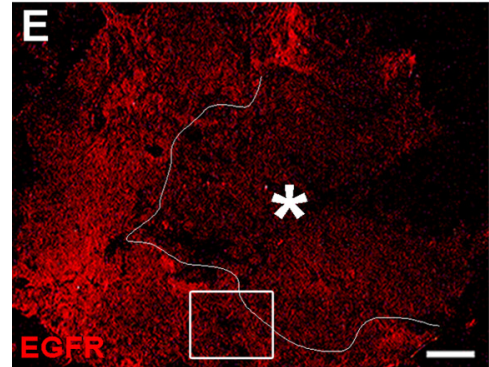

3 DPI Lesion Border

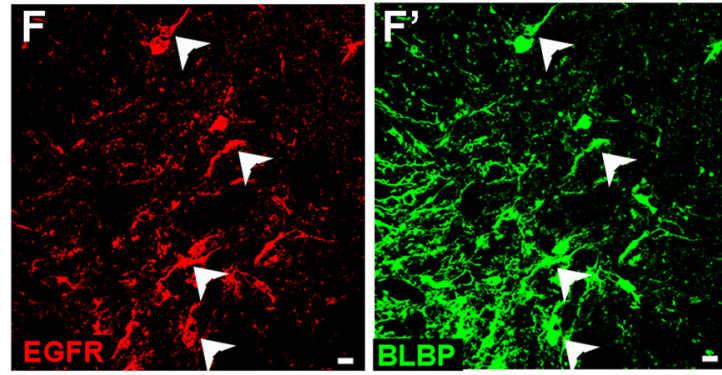

3 DPI White Matter
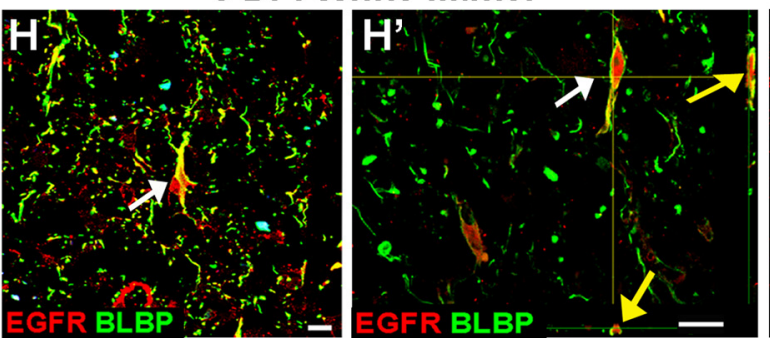

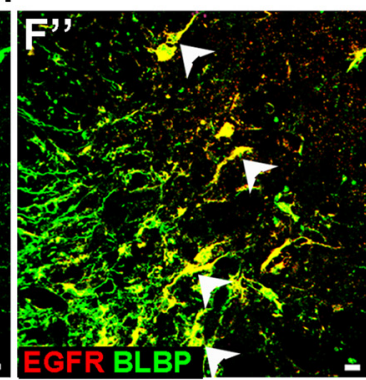

3 DPI CC

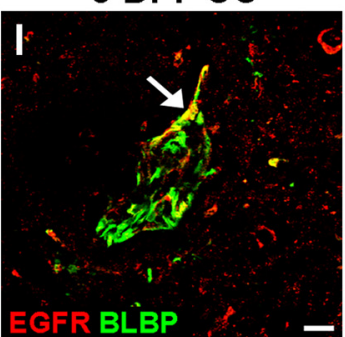

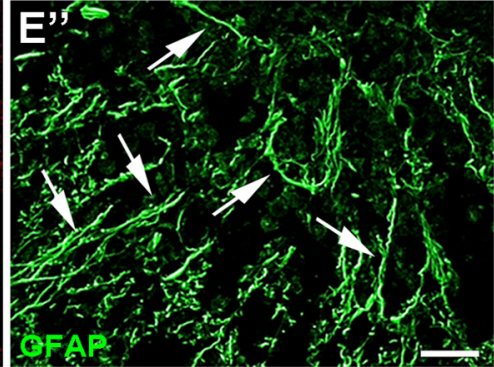

7 DPI Border

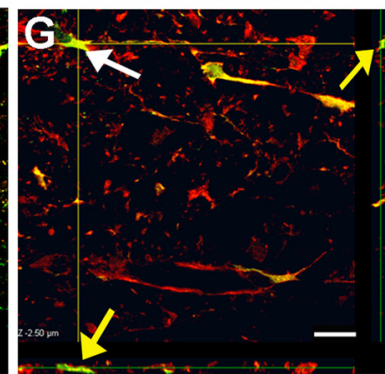

7 DPI CC

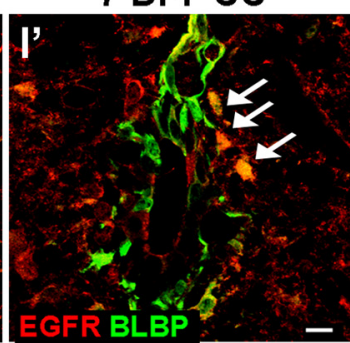

Figure 1. EGFR expression is increased and colocalized on astrocytes and progenitors at the lesion site after $\mathrm{SCl}$. $\boldsymbol{A}$, Western blots of naive (CtI) and injured spinal cord tissues showing a single band of $\sim 175 \mathrm{kDa}$ for EGFR, with $\beta$-tubulin $\left(\sim 50 \mathrm{kDa}\right.$ ) as a loading control. $\boldsymbol{B}$, EGFR expression is increased and remains high after spinal cord injury. AN0VA, $p<0.001 ;{ }^{*} p<0.05,{ }^{* *} p<0.01$ versus $\mathrm{Ctl}$ (post hoc tests). C, Wide-field fluorescence image of uninjured spinal cord white matter showing EGFR expression predominately in gray matter, including the neuropil throughout the ventral horn $\left(\mathrm{VH} ; \boldsymbol{C}^{\prime}\right)$ and punctate staining in lateral white matter (LWM; $\left.\boldsymbol{C}^{\prime \prime}\right)$. $\boldsymbol{D}-\boldsymbol{D}^{\prime \prime}$, Confocal microscopy shows EGFR expression in profiles throughout naive white matter (red; $\boldsymbol{D}$, arrows) is colocalized with $\mathrm{NF}+$ axons ( $\boldsymbol{D}^{\prime}$, blue; $\boldsymbol{D}^{\prime \prime}$, magenta profiles) but colocalization with astrocytes (GFAP, green) is rare. $\boldsymbol{E}$, During the first week after injury, EGFR expression is upregulated primarily in the spared white matter, with minimal expression in the lesion core $\left(^{*}\right) \cdot \boldsymbol{E}-\boldsymbol{E}^{\prime \prime}$, High-power confocal image enlargement of white box in $\boldsymbol{E}$ shows profiles in register reflecting EGFR $+\left(\boldsymbol{E}^{\prime}\right)$ and $G F A P+\left(\boldsymbol{E}^{\prime \prime}\right)$ astrocyte processes. $\boldsymbol{F}-\boldsymbol{F}^{\prime \prime}$, Confocal micrograph at the lesion border at 3 DPI depicting EGFR + profiles $(\boldsymbol{F})$ colocalized with BLBP + cells of astrocyte lineage $\left(\boldsymbol{F}^{\prime}, \boldsymbol{F}^{\prime \prime}\right.$, white arrowheads). $\mathbf{G}$, Confocal projection through a $10-\mu \mathrm{m}$-thick slice showing BLBP+/EGFR + astrocytes at the lesion border; a colabeled cell (white arrow) projected along the right and bottom borders of the image (yellow arrows). $\boldsymbol{H}$, Examples of BLBP $+/$ EGFR + cells and z-stack from spared white matter at 3 DPI. I, J, Confocal micrographs of the central canal rostral to the injury epicenter with BLBP $+/$ EGFR + cells at 3 and 7 DPI. Scale bars: $\boldsymbol{C}, \boldsymbol{E}, 50 \mu \mathrm{m} ; \boldsymbol{C}^{\prime}, \boldsymbol{D}, \boldsymbol{F}, \boldsymbol{H}^{\prime}, \boldsymbol{I}^{\prime}, 10 \mu \mathrm{m} ; \boldsymbol{C}^{\prime \prime}, \boldsymbol{G}, \boldsymbol{H}^{\prime}, \boldsymbol{I}^{\prime}, 20 \mu \mathrm{m}$. 
sion length, BrdU + cell counts at rostral and caudal borders, wound closure assays, and BMS scores over time were compared using two-way ANOVA with repeated measures (Scheff et al., 2003; Basso et al., 2006) followed by Bonferronicorrected $t$ tests. For all statistical analyses, significance was set at $p<0.05$. Power analyses for behavioral studies were performed using Statmate 2.0 (GraphPad Software).

\section{Results}

EGFR is upregulated early after injury on progenitor cells and astrocytes To establish the time course of EGFR expression after contusion, Western blots were performed on tissue from naive spinal cord and spinal cords obtained at 4, 7, and 15 DPI. EGFR expression was significantly increased at 4 DPI and remained high through 15 DPI (Fig. $1 A, B$ ). The distribution of EGFR immunoreactivity was determined using antibodies against EGFR, GFAP (mature and reactive astrocytes), BLBP [immature and reactive astrocytes (White et al., 2010)], and NF (axons) (Fig. $1 C-I)$. In naive tissue, EGFR immunoreactivity was low, with the greatest expression in gray matter, where it was associated primarily with neuronal profiles such as those in the ventral horn (Fig. 1C). In white matter regions (lateral white matter), uninjured axons expressed EGFR, as observed by colabeling of EGFR with NF antibodies (Fig. $\left.1 C^{\prime}, D\right)$. After contusion injury, EGFR immunoreactivity was dramatically increased injuryborder, where it was expressed mostly by astrocytes and astrocyte precursor cells (Fig. $1 E-I$ ). EGFR immunostaining was colocalized with GFAP + cells and processes in white matter (Fig. 1E) and with BLBP+ cells along the lesion border and throughout the spared white matter (Fig. $1 F-H$ ) and near the ependymal region surrounding the central canal rostral and caudal to the injury site (Fig. 1I). Thus, astrocyte progenitors and astrocytes represent primary targets of EGF ligand activation during the first week after SCI.

TGF $\alpha$ is a potent mitogen for adult spinal cord neural progenitor cells and astrocytes

To determine the direct effects of EGFR activation on the neural progenitors and astrocytes from adult spinal cord, we prepared purified cultures of adult-derived spinal cord progenitor cells (ASPNPCs) and astrocytes and exposed them to $1-50 \mathrm{ng} / \mathrm{ml}$ concentrations of TGF $\alpha$ for 3-5 d. TGF $\alpha$ has been shown previously to induce proliferation of forebrain neural progenitor cells (Anchan et al., 1991; Reynolds and Weiss, 1992) and primary cortical astrocytes (Sharif et al., 2006, 2007), but effects on neural progenitor cells and astrocytes from the adult spinal cord have never been described. TGF $\alpha$ induced robust proliferation of ASCNPCs in a dose-dependent manner (Fig. $2 A, B$ ), such that $96 \pm 4 \%$ of these cells incorporated BrdU after incubation in $25 \mu \mathrm{g} / \mathrm{ml}$ TGF $\alpha$. This response was specific to activation through the EGFR, as application of the EGFR inhibitor AG1478 blocked the

\section{BrdU+ Profiles: 3 Days of Treatment}

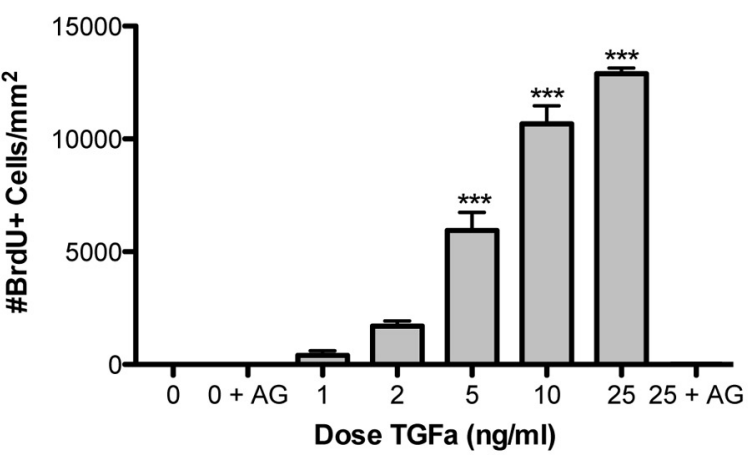

ASCNPCs

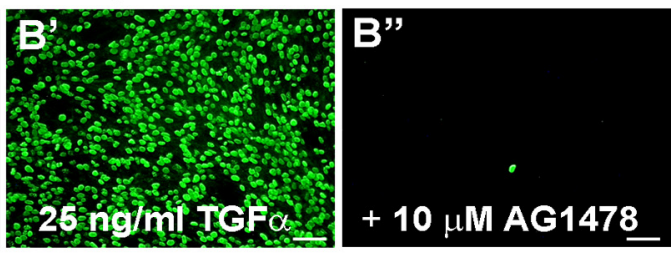

Astrocytes

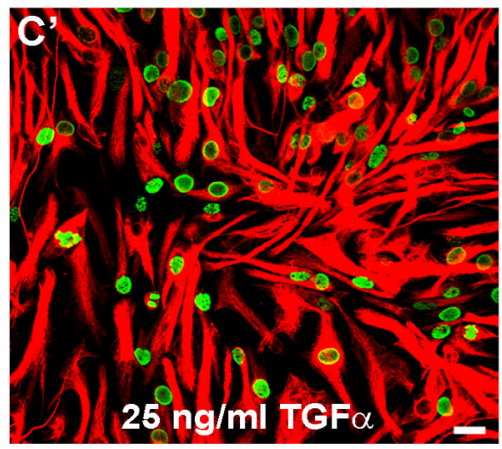

Figure 2. TGF $\alpha$ is a potent mitogen for ASCNPCs and astrocytes. A, Dose-response experiment shows the number of BrdU+ profiles $3 \mathrm{~d}$ after treatment with TGF $\alpha$ alone, or with the addition of $10 \mu \mathrm{M} \mathrm{AG1478}(+\mathrm{AG}) .{ }^{* * *} p<0.001$, ANOVA and post hoc

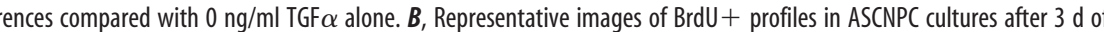
or $25 \mathrm{ng} / \mathrm{ml}$ TGF $\alpha$ with or without $10 \mu \mathrm{m} \mathrm{AG1478.} \mathrm{C,} \mathrm{C',} \mathrm{Representative} \mathrm{confocal} \mathrm{images} \mathrm{showing} \mathrm{BrdU+}$ ocytes (GFAP +) in the presence of $10 \% \mathrm{FBS}(\boldsymbol{C})$ or $25 \mathrm{ng} / \mathrm{ml} \mathrm{TGF} \alpha\left(\boldsymbol{C}^{\prime}\right)$, stained with GFAP (red) and BrdU (green). Scale bars:

effect (Fig. $\left.2 B^{\prime \prime}\right)$. TGF $\alpha$ also directly stimulated proliferation of astrocytes; cultures maintained in FBS without TGF $\alpha$ did not incorporate BrdU administered $6 \mathrm{~h}$ before fixation, whereas $\sim 60 \pm 7 \%$ of plated astrocytes treated with $50 \mathrm{ng} / \mathrm{ml}$ TGF $\alpha$ incorporated BrdU (Fig. 2C).

TGF $\alpha$ induces wound closure in adult spinal cord neural progenitor cells and mixed glial cells, but not in astrocytes Increased proliferation and migration may contribute to improved wound closure and formation of glial bridges after injury. To test this in vitro, confluent cultures were subjected to a scratch wound and treated with control medium or TGF $\alpha$. TGF $\alpha$-treated ASCNPCs demonstrated wound closure as early as $48 \mathrm{~h}$ after scratching and near complete filling of the scratch area by $3 \mathrm{~d}$ of treatment in a dose-dependent manner (Fig. $3 A, B$; treatment, time, and interaction effects; $p<0.001)$. Cell nuclei stained with DAPI (data not shown) were prevalent within the scratch area after TGF $\alpha$ treatment, suggesting that both proliferation and migration contributed to wound closure. Mixed glial cultures that were exposed to TGF $\alpha$ exhibited partial wound closure by $5 \mathrm{~d}$ of 
ASCNPCs
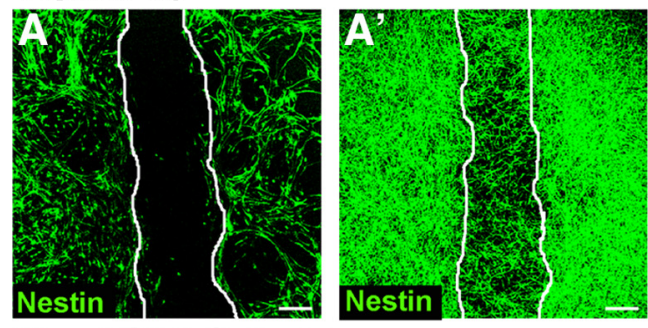

Mixed Glial Cultures
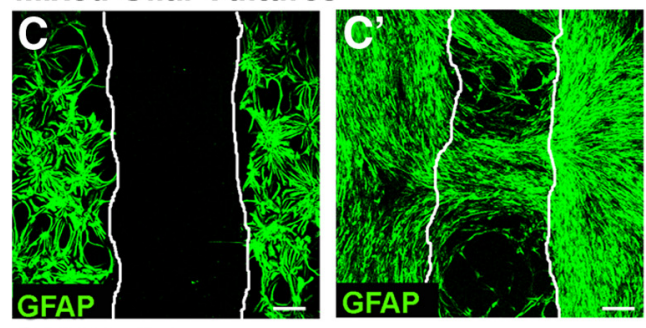

Astrocytes
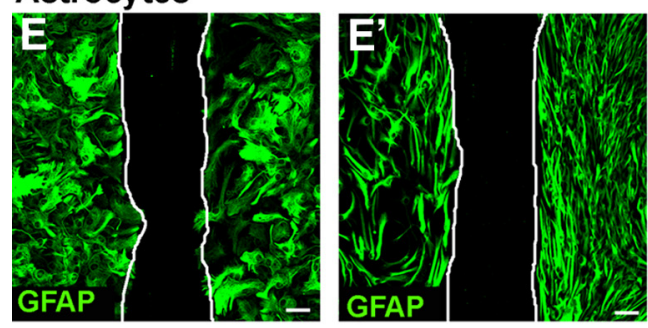

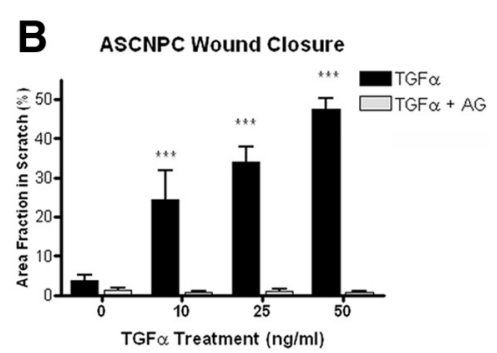

D Mixed Culture Wound Closure
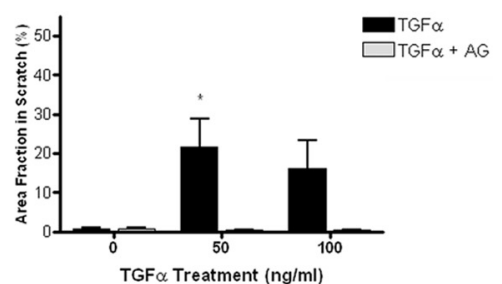

F Astrocyte Wound Closure

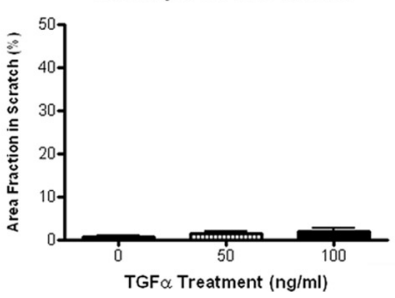

Figure 3. TGF $\alpha$ encourages wound closure in confluent ASCNPC and mixed glial cell cultures. $A, A^{\prime}$, Confocal images of nestin immunoreactivity in ASCNPC cultures without $(\boldsymbol{A})$ and with $\left(\boldsymbol{A}^{\prime}\right) 25 \mathrm{ng} / \mathrm{ml} \mathrm{TGF} \alpha$ present in the medium for $3 \mathrm{~d}$. White lines depict borders used for analysis. $\boldsymbol{B}$, TGF $\alpha$ induces a dose-dependent wound closure response that is blocked by AG1478 (ANOVA treatment, dose, interaction; posthoc, $\left.{ }^{* * *} p<0.001\right) . C, C^{\prime}$, GFAP immunoreactivity reveals formation of glial bridges in mixed cultures with progenitors and astrocytes incubated with TGF $\alpha$ for 5 d. D, TGF $\alpha$ increases wound closure (ANOVA, $p<0.05$ ), with significant post hoc difference at the $50 \mathrm{ng} / \mathrm{ml}$ dose $(p<0.05)$. Migration is blocked by AG1478. $\boldsymbol{E}, \boldsymbol{E}^{\prime}$, Fully differentiated astrocytes switch from polygonal morphology seen in $10 \% \mathrm{FBS}(\boldsymbol{E})$ to an elongated morphology resembling radial glia when incubated $5 \mathrm{~d}$ in $25 \mathrm{ng} / \mathrm{ml} \mathrm{TGF} \alpha\left(\boldsymbol{E}^{\prime}\right) . \boldsymbol{F}$, Astrocytes do not migrate into the scratch area. Scale bars, $50 \mu \mathrm{m}$.

treatment (Fig. 3C,D; treatment effect; $p<0.05$ ). In these cultures, which model the mixed population of progenitor cells and astrocytes found near the lesion edge early after spinal cord injury, streams of cells resembling glial bridges were found spanning from one side to the other within the wound area (Fig. $3 C^{\prime}$ ). In contrast, when fully differentiated astrocytes were incubated in TGF $\alpha$ for as long as $5 \mathrm{~d}$, there was no migration or filling of the wound site. A distinct border was present between the astrocytes and the scratch, and little to no process extension or cell migration occurred (Fig. $3 E, F$ ). Despite the lack of migration, the effects of TGF $\alpha$ on proliferation and changes in morphology of the astrocytes were evident after wounding (Fig. $3 E, E^{\prime}$ ).

TGF $\alpha$ alters cell morphology and marker expression in adult spinal cord neural progenitor and astrocyte cultures

Radial glia, the immature cells that support axonal growth during development (Vaccarino et al., 2007), have an elongated, bipolar phenotype and express BLBP, whereas mature astrocytes exhibit multiple processes and primarily express GFAP (Barry and McDermott, 2005; White and Jakeman, 2008). ASCNPC cultures are normally maintained at low density in proliferation medium containing EGF, FGF-2, and heparin, with frequent passaging. Under these conditions, they maintain mulitpotency and express very low levels of GFAP (Ray and Gage, 2006). However, when maintained in proliferation medium for several days without pas- saging, they increased expression of GFAP and expressed high levels of BLBP at confluency (Fig. 4A,C). When subsequently deprived of all growth factors, these cells proliferated slowly, but individual cells expressed similar intensity of GFAP immunoreactivity at $24 \mathrm{~h}$ after starvation (Fig. $4 A^{\prime}$ ), while they dramatically decreased expression of BLBP (Fig. $4 C^{\prime}$ ). ASCNPCs treated with TGF $\alpha$ for $3 \mathrm{~d}$ proliferated and also exhibited reduced GFAP expression compared with cells grown in normal growth medium or deprived of growth factors (Fig. $4 A^{\prime \prime}, B$ ). The ASCNPCs maintained in TGF $\alpha$ had slightly thinner processes that were sometimes in alignment when compared directly to those in normal proliferation medium (Fig. $4 A, A^{\prime \prime}$ ). These observations suggest that while inducing proliferation, TGF $\alpha$ may help maintain ASCNPCs in a relatively undifferentiated state.

Fully differentiated ASCNPC-derived astrocytes maintained in 10\% FBS with no TGF $\alpha$ exhibited a flattened, polygonal morphology that stained positively for GFAP but showed very low expression of BLBP (Fig. 4E, G). When deprived of FBS and all growth factors, these cells remained multipolar but developed densely stained, slender processes suggestive of stress fiber formation (Fig. $4 E^{\prime}, G^{\prime}$ ). Under these conditions the astrocytes upregulated both GFAP and BLBP (Fig. $4 F, H$ ). However, in the presence of TGF $\alpha$, they showed a further increase in expression of both GFAP and BLBP and developed a marked bipolar morphology similar to that of radial glia (Fig. $\left.4 E^{\prime \prime}, G^{\prime \prime}\right)$. Thus, differentiated astrocytes increase expression of both GFAP and BLBP as they undergo marked transformation to a bipolar morphology.

\section{TGF $\alpha$ does not elicit neuronal or oligodendroglial lineage differentiation of ASCNPCs}

Past studies have shown that neonatal brain progenitors cultured in the presence of TGF $\alpha$ can differentiate into both neuronal and glial cells (Reynolds et al., 1992). ASCNPCs treated with TGF $\alpha$ were immunolabeled with $\beta$-III tubulin to identify neuronal cells and NG2 to identify oligodendrocyte precursor cells. In either control or TGF $\alpha$ conditions, $\beta$-III tubulin immunostaining was not present. All cultures showed some basal NG2 expression, but this expression level did not change with treatment (data not shown).

TGF $\alpha$-treated ASPNPCs and astrocytes are highly permissive for axonal growth

Based on in vitro observation that TGF $\alpha$ induces proliferation and a BLBP-expressing, elongated phenotype in adult astrocytes, we hypothesized that the transformed astrocytes would be permissive to axonal growth. Although axonal activation of the EGFR has been shown to restrain axon growth on inhibitory substrates, such as myelin and chondroitin sulfate proteoglycans (Koprivica et al., 2005), the effects of EGFR activation on a sup- 


\section{ASCNPCs}
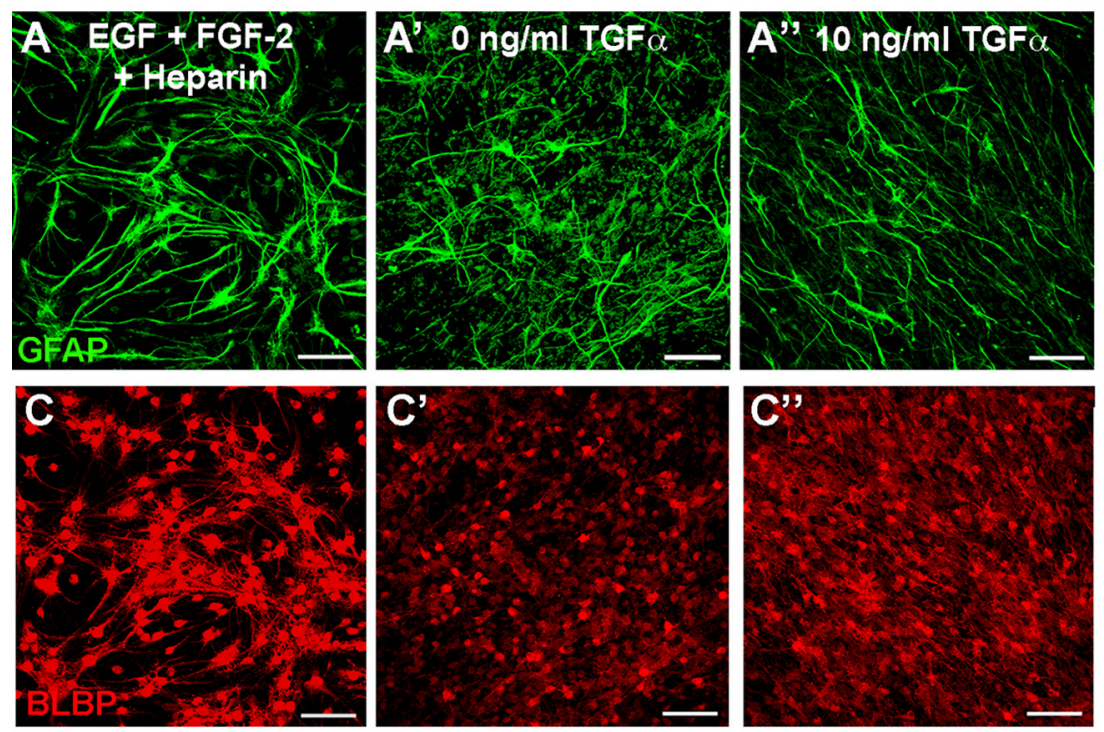

Astrocytes
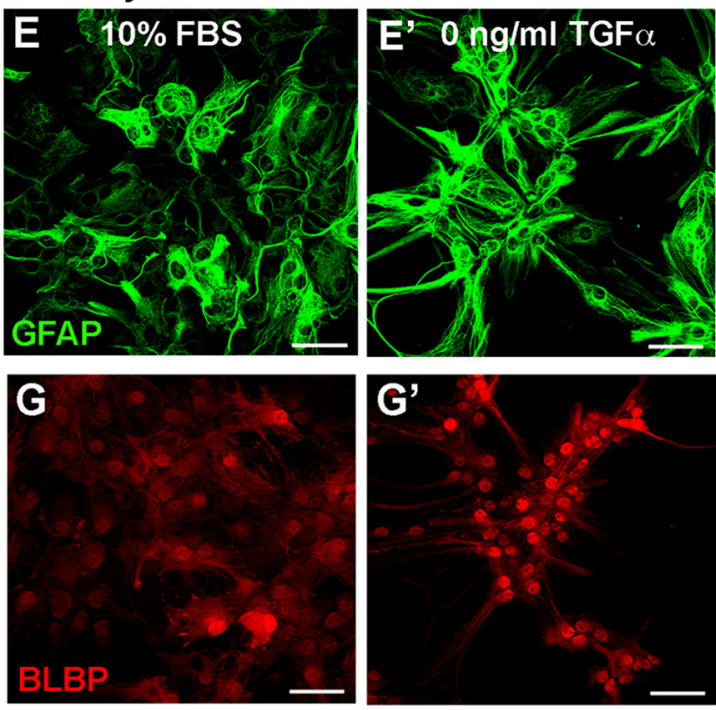
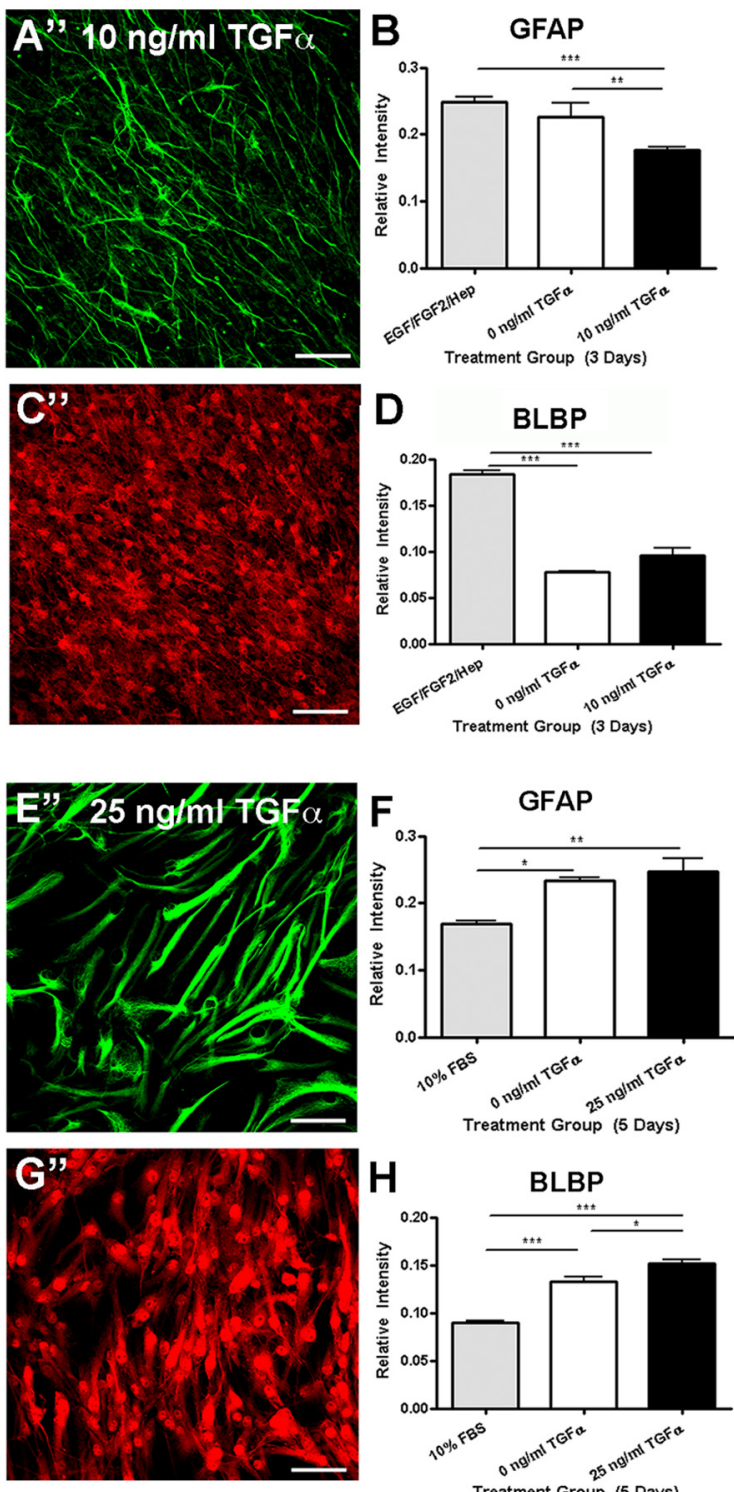

Figure 4. TGF $\alpha$ induces elongation of both ASCNPCs and astrocytes while exerting opposite effects on astrocyte marker expression intensity. $\boldsymbol{A}$, ASCNPCs stained with anti-GFAP develop elongated and aligned processes after incubation in $10 \mathrm{ng} / \mathrm{ml} \mathrm{TGF} \alpha$. B, Decreased expression of GFAP staining intensity with TGF $\alpha$ treatment. $\boldsymbol{C}, \boldsymbol{D}$, ASPNPCs show decreased BLBP expression with serum starvation $\left(\boldsymbol{C}^{\prime}\right)$ and no additional change after incubation in TGF $\alpha\left(\boldsymbol{C}^{\prime}\right)$. $\boldsymbol{E}-\boldsymbol{H}$, Differentiated astrocytes in FBS $(\boldsymbol{E}, \boldsymbol{G})$ become elongated with evidence of stress fiber formation when serum starved $\left(\boldsymbol{E}^{\prime}, \boldsymbol{G}^{\prime}\right)$. In contrast, they develop into radial glia-like elongated profiles after treatment for $5 \mathrm{~d}$ with $25 \mathrm{ng} / \mathrm{ml} \mathrm{TGF} \alpha\left(\boldsymbol{E}^{\prime \prime}, \boldsymbol{G}^{\prime \prime}\right)$. Both GFAP $(\boldsymbol{F})$ and BLBP $(\boldsymbol{H})$ stain intensity is increased after removal of FBS and further enhanced with the addition of $25 \mathrm{ng} / \mathrm{ml} \mathrm{TGF} \alpha . p<0.05$ for all graphs (ANOVAs). ${ }^{*} p<0.05,{ }^{* *} p<0.01,{ }^{* * *} p<0.001$ (post hoc comparisons). Scale bars, $50 \mu \mathrm{m}$.

portive substrate, such as laminin, has not previously been tested. DRGs were plated on coverslips coated with laminin in the presence and absence of TGF $\alpha$. Neurite survival and outgrowth were not affected by TGF $\alpha$ treatment on this growth-permissive substrate (Fig. $5 A, D$ ). Then, we treated both ASCNPCs and astrocytes with TGF $\alpha$, or maintained them in proliferation medium or $10 \%$ FBS, respectively; we then removed the incubation medium and plated adult DRG cells on these cultures in DRG medium for $24 \mathrm{~h}$. Compared with laminin alone, astrocytes maintained in $10 \%$ FBS were inhibitory to axon growth (Fig. 5A, B,D, Astros/ FBS). In contrast, neurite outgrowth from DRGs plated on TGF $\alpha$-treated astrocytes (Astros/25) was similar to those grown directly on laminin. In cultures stained with GFAP and NF antibodies, neurites followed the GFAP-labeled cell profiles (Fig. $5 B, C)$. Those grown on astrocytes treated with FBS were highly branched and restricted predominantly to the surface of single astrocytes (Fig. 5B), whereas those plated on TGF $\alpha$-treated astrocytes had more elongated processes which extended from cell to cell in the astrocyte layer (Fig. 5C). Thus, TGF $\alpha$ switches the astrocyte phenotype from a stellate morphology with growthinhibitory properties to an elongated or radial-like and growthpermissive phenotype.

TGF $\alpha$-AAV increases TGF $\alpha$ expression at the site of injury To determine the effects of directly targeting astrocyte transformation by TGF $\alpha$ in vivo, TGF $\alpha$-AAV or GFP-AAV particles were delivered via microinjection of $2 \mu \mathrm{l}$ into the gray matter immediately at two sites just rostral and caudal to the future site of injury (Fig. 6A). GFP-AAV injected into the uninjured spinal cord parenchyma produced a GFP + infection site of $\sim 400-600$ $\mu \mathrm{m}$ in diameter (Fig. $6 B$ ). RT-PCR was used to confirm expression of the human TGF $\alpha$ transgene in spinal cord tissues har- 


\section{A Laminin only}
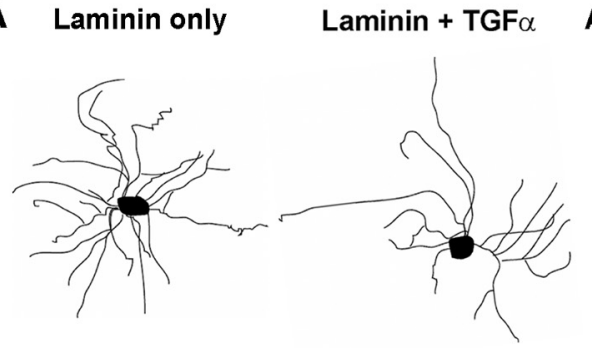

\section{Astrocytes prepared with $10 \%$ FBS}

Astrocytes treated
with $25 \mathrm{ng} / \mathrm{ml}$ TGF $\alpha$

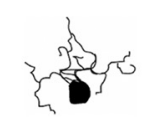

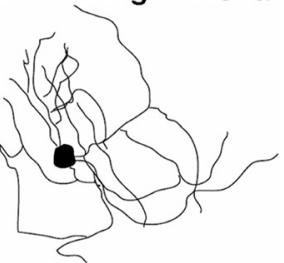
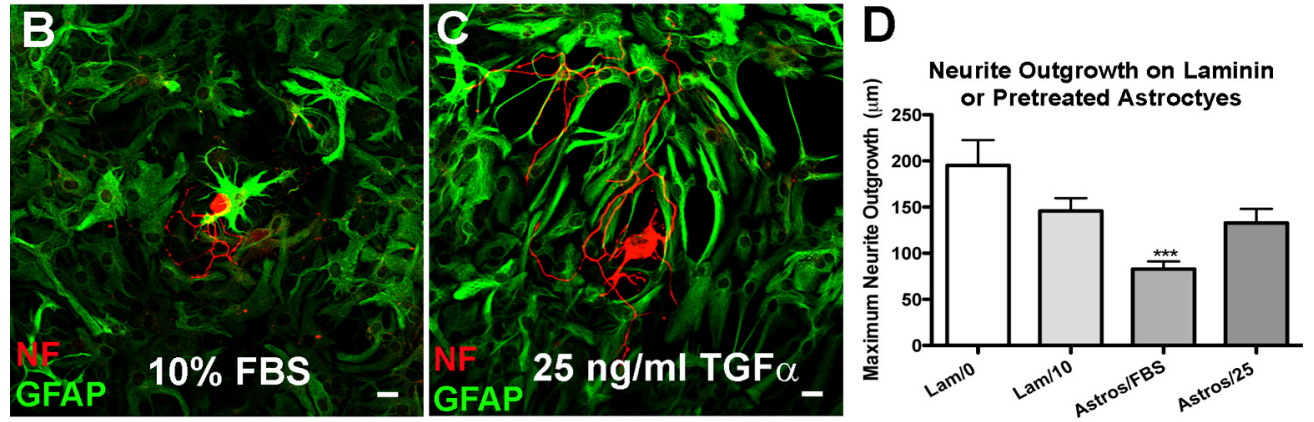

Figure 5. TGF $\alpha$-transformed astrocytes support axonal growth. $A$, Camera lucida drawings of representative DRG neurons that were plated on cellular and acellular substrates, including laminin alone and laminin in the presence of $10 \mathrm{ng} / \mathrm{ml} \mathrm{TGF} \alpha$, or on astrocytes pretreated with either $10 \% \mathrm{FBS}$ or $25 \mathrm{ng} / \mathrm{ml} \mathrm{TGF} \alpha$ before plating. $\boldsymbol{B}, \boldsymbol{C}$, Confocal images of NF + axons (red) plated for $24 \mathrm{~h}$ on astrocytes (green) after treatment in control medium (10\% FBS) or $25 \mathrm{ng} / \mathrm{ml}$ TGF $\alpha$ for $5 \mathrm{~d}$. Scale bars, $20 \mu \mathrm{m}$. $D$, The addition of TGF $\alpha$ did not inhibit neurite outgrowth of DRG neurons plated on laminin (Lam/10) compared with laminin with no TGF $\alpha$. In contrast, differentiated astrocytes prepared in $10 \%$ FBS (Astros/FBS) were inhibitory to axon growth. Astrocytes treated with $25 \mathrm{ng} / \mathrm{ml}$ TGF $\alpha$ for $5 \mathrm{~d}$ (Astros/25) were as permissive as those plated on laminin alone. $p<0.05$, ANOVA; ${ }^{* * *} p<0.001$, post hoc comparison.

vested from naive mice or 8 weeks after injury in mice that were injured 2 weeks after receiving TGF $\alpha$-AAV or GFP-AAV injections (Fig. 6C). Likewise, tissues prepared for ELISA verified a significant increase in TGF $\alpha$ expression in TGF $\alpha$-AAV-injected mice compared with either naive mice or mice receiving empty vector controls (eAAV) with or without prior SCI (Fig. 6D).

AAV of the type 1 serotype is known to infect neurons and astrocytes. When a SCI was performed $14 \mathrm{~d}$ after the injection and animals were perfused at 10 DPI, GFP was detected in both neurons (Fig. 6E, $E^{\prime \prime \prime}$ ) and some hypertrophied astrocytes (Fig. $\left.6 F, F^{\prime \prime \prime}\right)$ (Koerber et al., 2009; Blits et al., 2010).

\section{TGF $\alpha$-AAV alters the astrocyte border and affects exclusion of NF from the lesion site}

To determine whether overexpression of TGF $\alpha$-AAV can transform astrocytes after SCI, mice were given injections of TGF $\alpha$ AAV or GFP-AAV, injured 2 weeks later, and perfused at $10 \mathrm{DPI}$ for histological analyis, a time when newborn GFAP + astrocytes have accumulated at the edge of a contusion injury (White et al., 2010). GFP-AAV-injected mice showed robust staining at the lesion border corresponding to a dense plexus of hypertrophied $\mathrm{GFAP}+$ astrocytes. There were very few NF+ profiles beyond this border at this time (Fig. $7 A, A^{\prime \prime}$ ). In contrast, mice that received TGF $\alpha$-AAV injections had a distinctly altered glial border (Fig. $7 B, B^{\prime \prime}$ ). In saggital sections, astrocytes found along regions at the edges of the lesions were elongated and lacked an abrupt border; instead many GFAP + processes extended as far as 1-2 $\mathrm{mm}$ into the lesion (Fig. $7 B^{\prime \prime}$ ). The astrocyte profiles within this region were typically accompanied by NF+ axons, which were also occasionally found far from the edge of the disrupted tissue border (Fig. $\left.7 C^{\prime \prime}\right)$. We did not identify differences in BMS scores of TGF $\alpha$-AAV versus GFP-AAV mice at 1 DPI ( $2.2 \pm 0.7$ vs $2.2 \pm$ $0.6)$ or $10 \mathrm{DPI}(6.0 \pm 0.8$ vs $6.2 \pm 0.7 ; n=3$ per group), suggesting that changes to the lesion border alone did not support functional regeneration.
The effects of TGF $\alpha$-AAV on the glial response were examined further in two additional experiments with injured mice that received either TGF $\alpha$-AAV or PBS (Experiment 2) or TGF $\alpha$ AAV or eAAV (Experiment 3). All mice were perfused at 10 DPI, and tissues spanning the entire injury site were sectioned in the transverse plane. As suggested from the GFP-AAV results, TGF $\alpha$ did not appear to impact locomotor recovery at 10 DPI (BMS: $\mathrm{TGF} \alpha, 5.1 \pm 0.26$; PBS, $4.8 \pm 0.17$; eAAV, $4.0 \pm 0.58$; posttest analysis of $90 \%$ power for detecting a 1-point difference at $\alpha<$ 0.05 for unpaired comparison with $n=6$ but only $60 \%$ power with $n=3$ ).

Importantly, however, as illustrated in the series of GFAPstained sections (Fig. 7C) and Cavalieri volume estimates (Fig. $7 D)$, the GFAP-free lesion volume was altered across groups (ANOVA, $p<0.05$ ) and was smallest in the TGF $\alpha$-AAV-treated subjects. Thus, TGF $\alpha$ overexpression clearly modified the astrocyte border, either by enhancing astrocyte migration or sparing astrocyte retraction from the lesion core.

We then hypothesized that this reduction in the GFAP-free region would provide a permissive environment for damaged or growing axons. Indeed, analysis of equally spaced NF-stained sections revealed overall differences in the density of axons across groups (repeated-measures ANOVA, $p<0.05$ ) and increased axon density in TGF $\alpha$-AAV-treated mice compared with either of the control groups, which was different by post hoc analysis at $0.4 \mathrm{~mm}$ rostral to the epicenter (Fig. $7 E, F$ ). Whereas the group means demonstrated a significant increase in axonal density only at the rostral border, examination of individual sections revealed scattered NF+ axons among the occasional astrocyte profiles extending from the ventral and caudal edges of the lesion as well.

Growing axons in the lesion site are associated with newborn astrocytes

Qualitative staining was done to further describe potential sources of axons and the substratum within the lesion (Fig. 8). As 
A

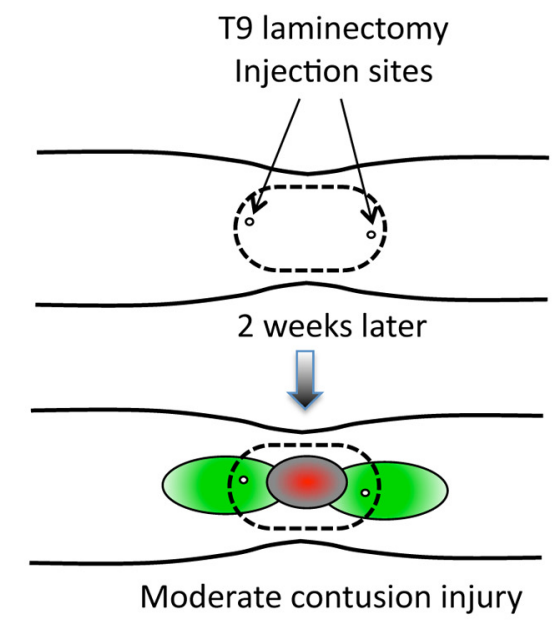

B

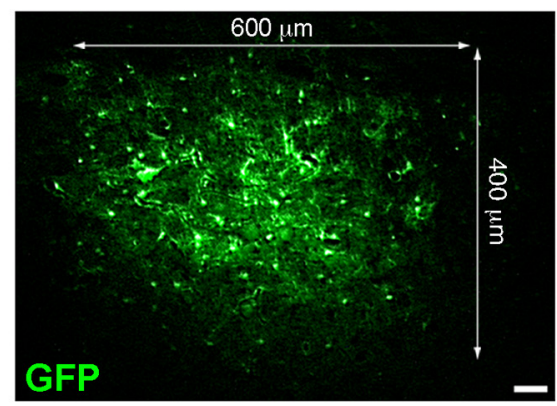

D

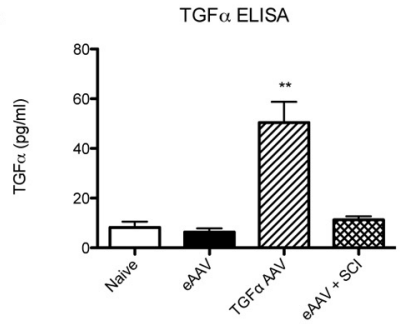

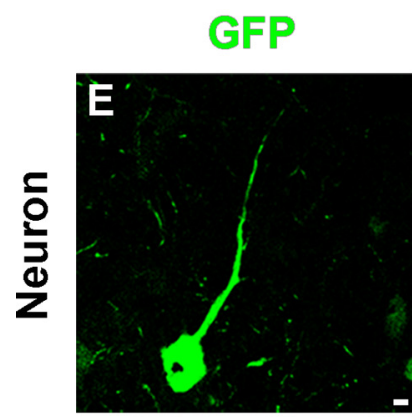
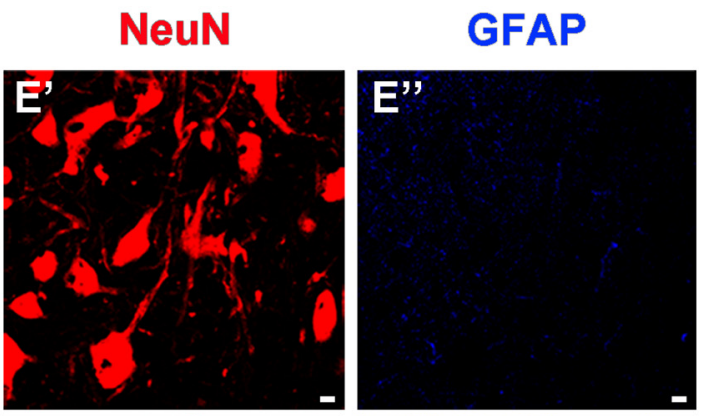

Merge
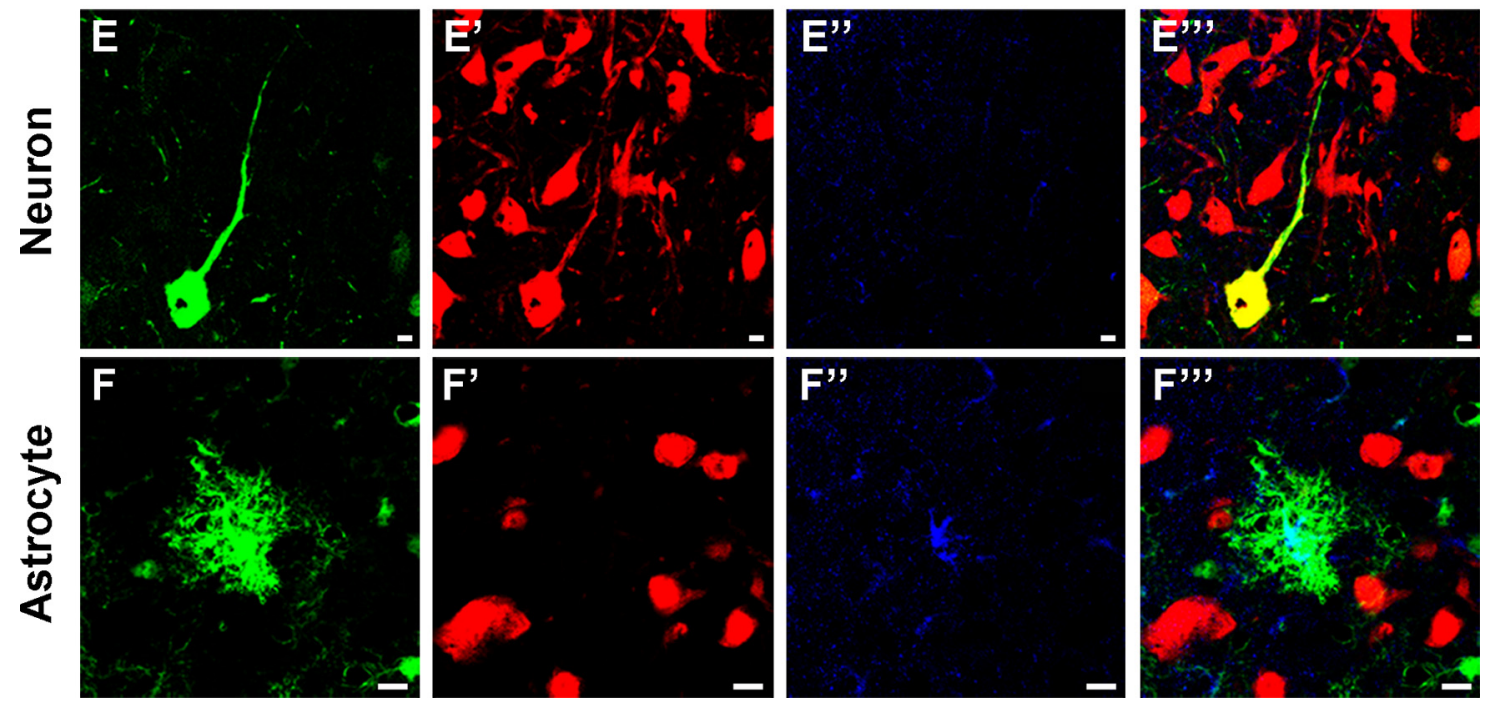

Figure 6. AAV is incorporated into spinal cord neurons and astrocytes and increases TGF $\alpha$ mRNA and peptide expression after SCI. A, Schematic showing location of injection sites at the T9 laminectomy site (top) and the estimated viral spread (bottom, green) and site of contusion injury administered 2 weeks later (gray/red oval). $\boldsymbol{B}$, Representative size of GFP-AAV injection site in midthoracic spinal cord at 2 weeks after injection. C, RT-PCR of human TGF $\alpha$ mRNA expression after AAV injection and SCI. + Control, TGF $\alpha$-transfected HEK 293 cells; Naiive, naive tissue. D, Results of ELISA confirm expression of TGF $\alpha$ peptide in spinal cord at 2 weeks after TGF $\alpha$-AAV injection, compared with naive spinal cord, laminectomy with eAAV, or $10 \mathrm{~d}$ after SCl after eAAV injection. Values represent mean \pm SEM for two to three samples per group; ${ }^{*} \boldsymbol{p}<0.05$. $\boldsymbol{E}, \boldsymbol{F}$, Confocal images of GFP $(\boldsymbol{E}, \boldsymbol{F}), \operatorname{NeuN}\left(\boldsymbol{E}^{\prime}, \boldsymbol{F}^{\prime}\right)$, and GFAP $\left(\boldsymbol{E}^{\prime \prime}, \boldsymbol{F}^{\prime \prime}\right)$ showing neurons and astrocytes expressing GFP 2 weeks after GFP-AAV injection. Scale bars: $\boldsymbol{B}, 50 \mu \mathrm{m} ; \boldsymbol{E}, \boldsymbol{F}, 5 \mu \mathrm{m}$.

described previously (Ma et al., 2004; White et al., 2008), TGF $\alpha$ AAV and control specimens exhibited a laminin-enriched matrix at the lesion border at $10 \mathrm{~d}$ after contusion injury. Section and volume analysis revealed no significant difference in the area or volume of laminin staining between TGF $\alpha$-AAV- and PBStreated specimens (data not shown). However, throughout the lesion border regions, there was a close association of laminin and GFAP, and these profiles were closely associated with numerous GAP43 + axons (Fig. 8A, $A^{\prime}$ ) with elongated astrocyte profiles resembling the permissive astrocyte profile seen after TGF $\alpha$ treatment of astrocytes in vitro (Fig. $8 C$, arrows).

To assess whether any of these axons were centrally derived, sections were coimmunolabeled with 5-HT and GFAP antibodies. Confocal micrographs revealed $5-\mathrm{HT}+$ axons associated with astrocytes primarily near the rostral lesion border in both treatment groups, but occasionally extending further into the lesion, and comingled with increased GFAP + astrocytes in the TGF $\alpha$ AAV-treated mice (Fig. $8 B$ ).

A targeted mechanism of bridge formation is to increase the proliferation of cells at the lesion border. To determine whether $\mathrm{NF}+$ axons were associated with astrocytes born after contusion injury, BrdU was injected intraperitoneally at $3 \mathrm{DPI}$, and sections obtained at 10 DPI were triple labeled with BrdU, BLBP, and NF. In both TGF $\alpha$-AAV and control specimens, many BrdU+ nuclei were confirmed newborn astrocytes with BLBP + colabeling in both $2 \mathrm{D}$ and projection stack confocal micrographs, and NF+ profiles were often found coursing along these newborn, elongated astrocytes (Fig. 8D-F,H). Next, sections costained with 

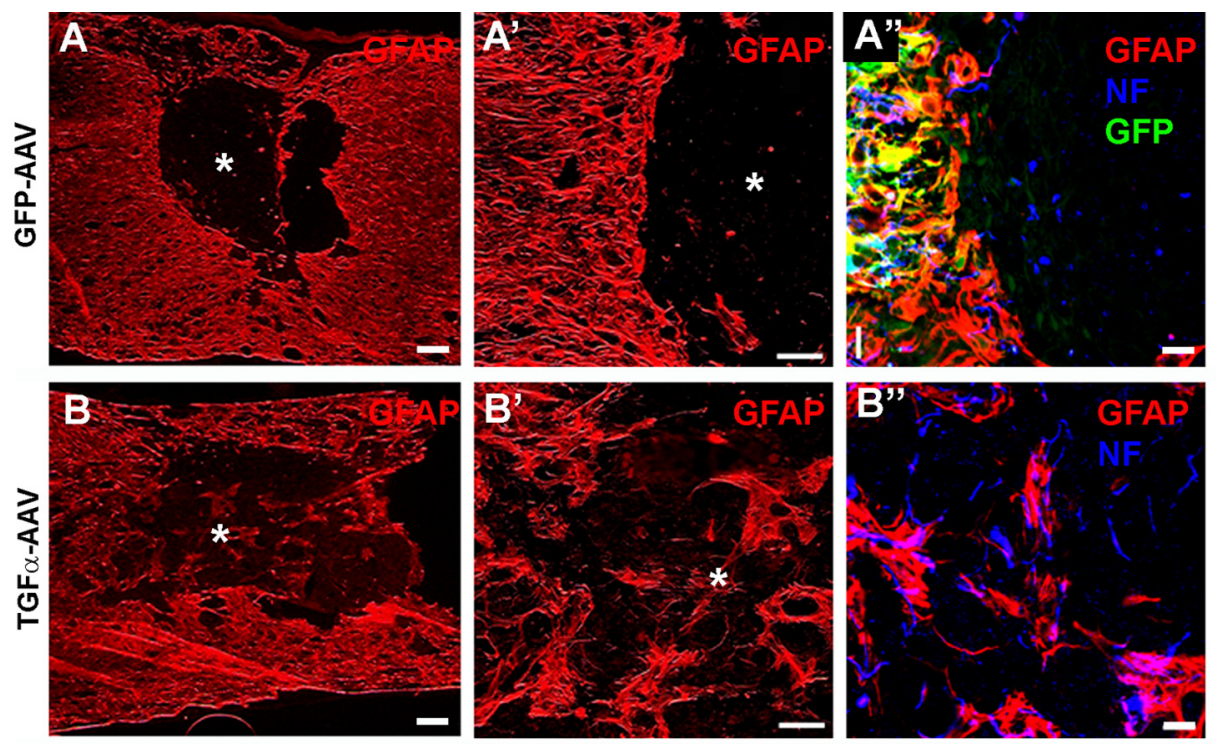

C

GFAP
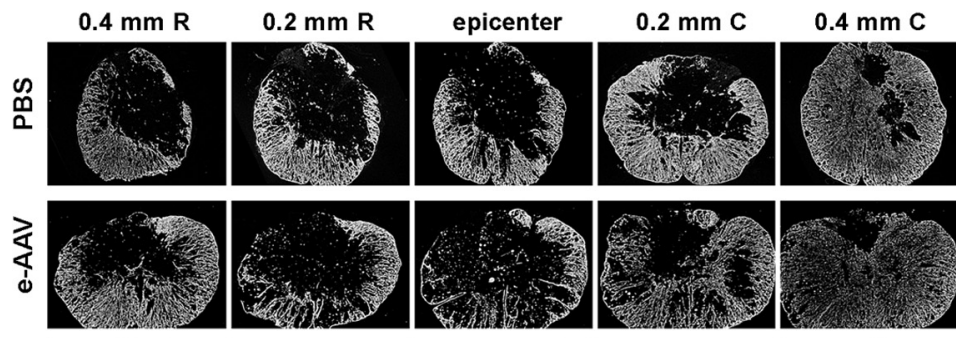

D
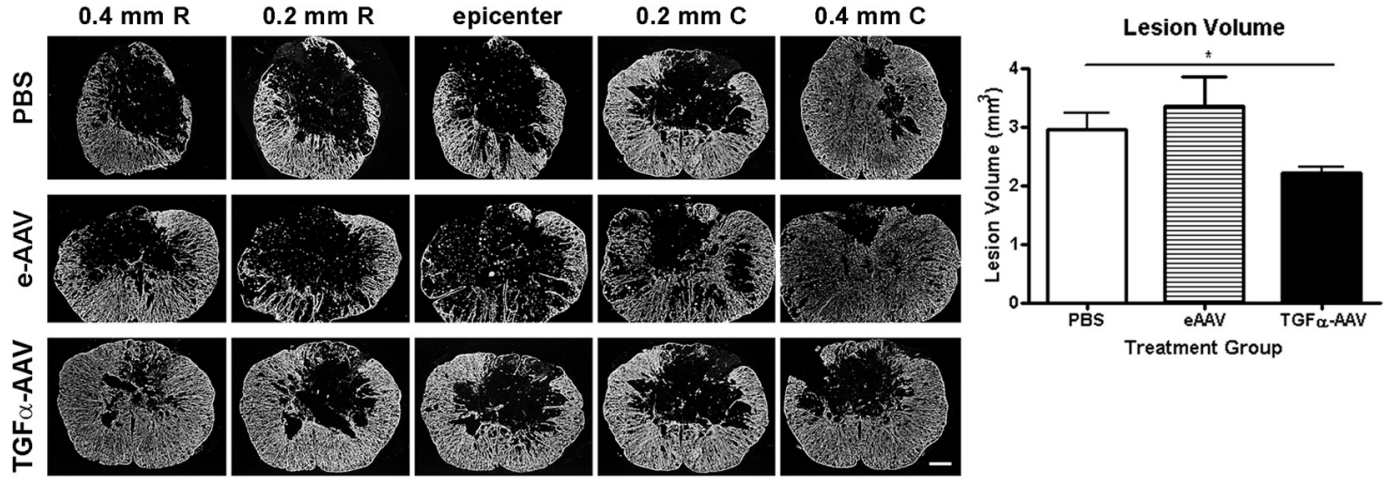

E

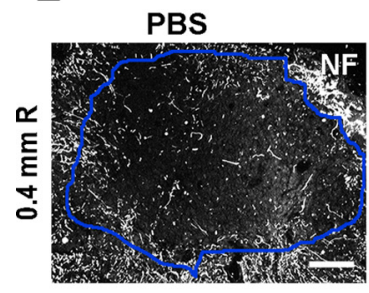

Neurofilament

$$
\text { e-AAV }
$$

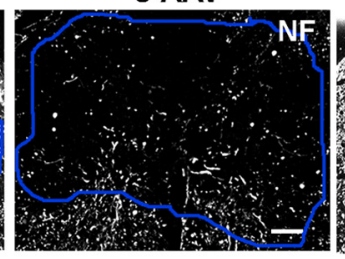

TGF $\alpha$-AAV

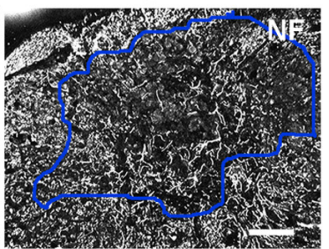

F

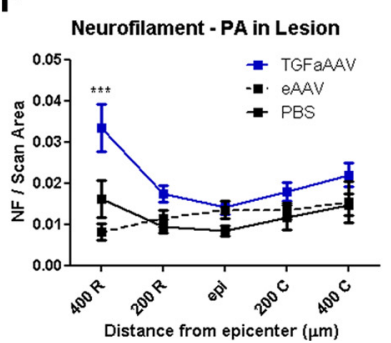

Figure 7. TGF-AAV increases astrocyte migration and axonal extension into the site of a contusion injury $\left(^{*}\right)$ at $10 \mathrm{DPI} . \boldsymbol{A}, \boldsymbol{B}$, Fluorescence images of longitudinal sections through the lesion border in GFP-AAV-treated $(\boldsymbol{A})$ and TGF $\alpha$-AAV-treated $(\boldsymbol{B})$ mice, stained with anti-GFAP. $\boldsymbol{A}^{\prime}, \boldsymbol{B}^{\prime}$, High-power images of the lesion edge. $\boldsymbol{A}^{\prime \prime}, \boldsymbol{B}^{\prime \prime}$, Confocal micrographs showing the relationship of astrocytes (GFAP, red), axons (NF, blue), and GFP expression (green) at the lesion border in GFP-AAV-treated $\left(\boldsymbol{A}^{\prime \prime}\right)$ and TGF $\alpha$-AAV-treated ( $\left.\boldsymbol{B}^{\prime \prime}\right)$ mice. $\boldsymbol{C}$, Representative images of GFAP immunoreactivity in cross sections from $0.4 \mathrm{~mm}$ rostral to $0.4 \mathrm{~mm}$ caudal to the lesion epicenter in PBS-, eAAV-, and TGF $\alpha$-AAV-treated mice. D, Volume of the GFAP-devoid region ( $n=3-9$ per group; $p<0.05$, ANOVA main effect; corrected post hoc tests nonsignificant). $E$, Images of NF immunoreactivity at the lesion border (0.4 mm rostral to the epicenter) from representative PBS-, eAAV-, and TGF $\alpha$-AAV-treated specimens. Blue outlines denote the area used to measure NF immunoreactivity. $F$, Proportional area (PA) of sample box occupied by NF profiles. $p<0.05$, two-way ANOVA main effects of treatment and distance across the lesion; ${ }^{*} p<0.05$ for TGF $\alpha$-AAV vs PBS and eAAV at $0.4 \mathrm{~mm}$ rostral to the epicenter (post hoc treatment effect). Scale bars: $A, B, 100 \mu \mathrm{m} ; \boldsymbol{A}^{\prime}, \boldsymbol{A}^{\prime \prime}, \boldsymbol{B}^{\prime}, \boldsymbol{B}^{\prime \prime}, 20 \mu \mathrm{m}$.

BLBP and BrdU antibodies were examined to determine whether TGF $\alpha$ increased proliferation at the lesion borders (Fig. 8G, $G^{\prime \prime}$ ). The effect of TGF $\alpha$ on cell proliferation at the targeted glial border was determined using a standard counting frame on sections spanning the rostral and caudal astrocyte borders. TGF $\alpha-\mathrm{AAV}$ treated mice had significantly more BrdU+ nuclei at the lesion edges than PBS- or eAAV-treated control specimens (Fig. 8G).
Mice lacking functional EGFR activity show impaired functional recovery, enlarged GFAP-free lesion, and decreased proliferation at the lesion borders after contusive SCI

Because overexpression of the EGFR ligand TGF $\alpha$ induced progenitor migration and a growth permissive environment in vitro and in vivo, we hypothesized that impaired EGFR signaling would 
result in deficits in astrocyte migration and impaired glial scar formation in vivo. $\mathrm{C} 57 \mathrm{BL} / 6^{\mathrm{EgfrVel}(+/-)}$ mice (Velvet) and WT controls received a moderate contusion, and locomotor recovery was measured using the BMS. There were no differences in weight before injury $(23.4 \pm 2.0 ; 24.7 \pm 1.5 \mathrm{~g})$ or at 3 weeks after injury $(19.7 \pm 1.4 ; 18.9 \pm 0.9 \mathrm{~g})$. Mice lacking the EGFR showed impaired recovery of locomotor function over time (Fig. 9A). Post hoc analysis revealed lower BMS scores all time points beginning at 10 DPI. Because BMS scores may be impacted by reduced activity, mice were assessed for total movement time and total distance traveled over 10 min using an activity box with infrared beams (Open Field system; Accuscan), and there were no effects of genotype on these measures (movement time of $285+30$ vs $291 \pm 15 \mathrm{~s}$ and total distance of $442.4 \pm 84.8$ vs $474.7 \pm 46.8 \mathrm{~cm}$ for Velvet and WT, respectively). GFAP immunostaining revealed expanded GFAP-negative regions in these specimens, sometimes extending deep into the white matter border of the EGFR dysfunctional (Velvet) mice (Fig. $9 B, C)$. The Velvet mice exhibited significantly larger lesions, defined by the GFAP-free area at the injury epicenter $\left(0.565 \pm 0.019\right.$ vs $0.684 \pm 0.054 \mathrm{~mm}^{2} ; t$ test $p<0.05 ; n=9-10$ per group). In addition, because proliferation is essential for scar formation (Faulkner et al., 2004), counts of BrdU+ nuclei at the rostral and caudal lesion borders revealed significantly fewer cells born at 3 DPI in the Velvet mice (Fig. 9D-F). Together, these outcome measures indicate that a fully functional EGFR is important for endogenous cell proliferation and formation of a glial border at the lesion epicenter and indicate that intrinsic EGFR activation contributes to the extent of functional recovery of locomotion after contusion injury.

\section{Discussion}

Astrocyte activation is now known to be essential for limiting the extent of inflammation and secondary injury after trauma (Pekny et al., 1999; Faulkner et al., 2004;

Okada et al., 2006; Herrmann et al., 2008). Phylogenetic and developmental models demonstrate the potential reparative role of glial progenitor cells and astrocytes in supporting regeneration after injury (Chernoff et al., 2003; Lane et al., 2007; Rehermann et al., 2009). Therefore, we sought to determine whether these same cell populations in the adult mouse spinal cord could be stimulated to proliferate and migrate toward the center of the lesion and support growing axons after contusion injury. If successful, this approach would serve as a first step toward the goal of enhancing supportive endogenous cellular bridges for guiding ax-
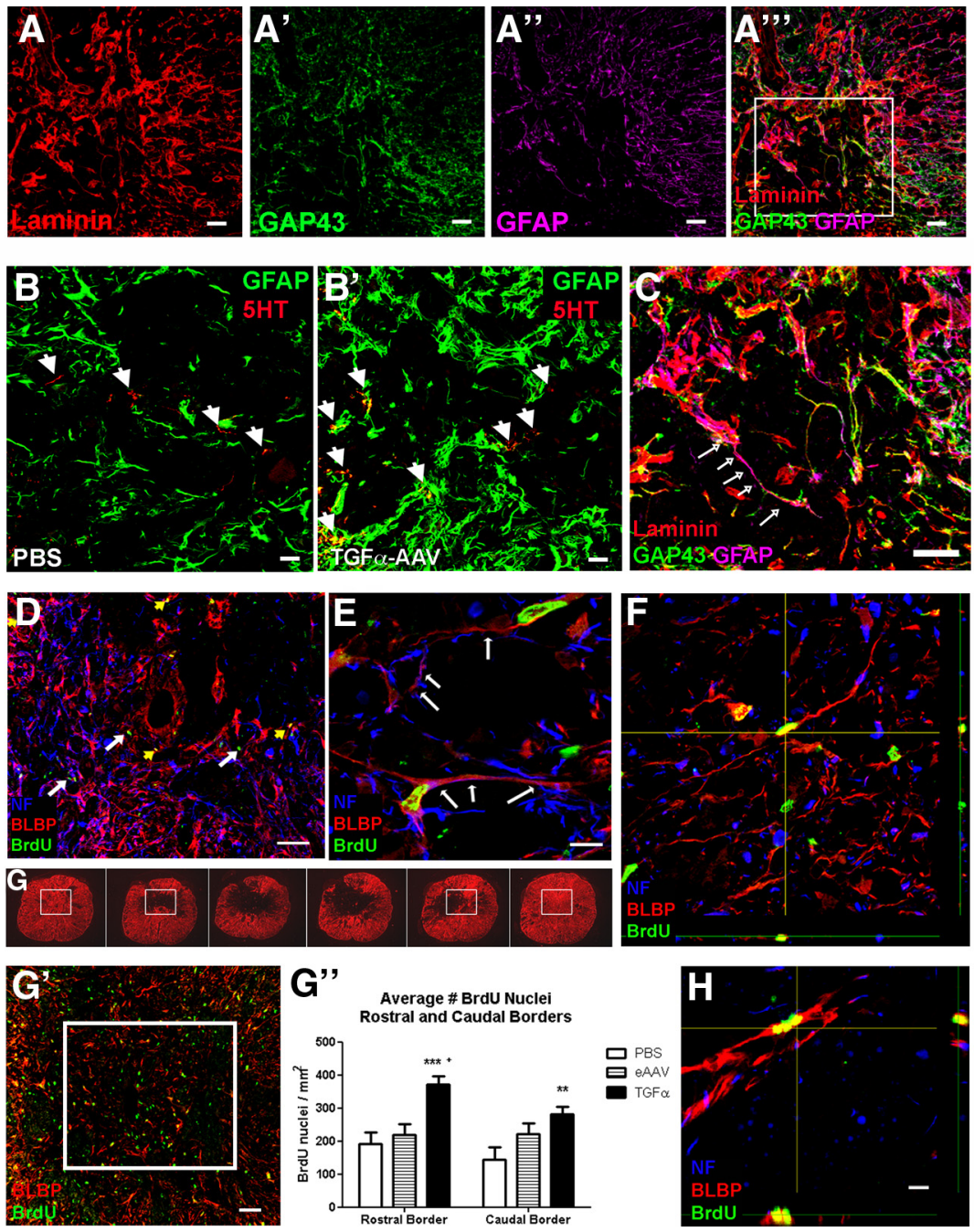

Figure 8. Axons growing along newborn astrocytes after TGF $\alpha$-AAV treatment. $A-A^{\prime \prime \prime}, C$, Confocal image of TGF $\alpha$-AAV-treated mouse section from just rostral to the injury epicenter. New axons (GAP43 + , green; $\boldsymbol{A}^{\prime}$ ) grow along GFAP + profiles (purple; $\boldsymbol{A}^{\prime \prime}$ ) in association with laminin (red; $\left.\boldsymbol{A}^{\prime}\right)$. $\boldsymbol{C}$, Enlargement from boxed area in $\boldsymbol{A}^{\prime \prime \prime}$ shows an axon profile along a GFAP $+/$ laminin + process (arrows). $\boldsymbol{B}, \boldsymbol{B}^{\prime \prime \prime}$, Confocal images of astrocytes (GFAP, green) and centrally derived axons (5-HT, red) at the lesion border of a PBS-treated $(\boldsymbol{B})$ and TGF $\alpha$-AAV-treated ( $\left.\boldsymbol{B}^{\prime}\right)$ specimen. 5-HT axons (arrowheads) are found both adjacent to and away from the GFAP + profiles within the lesion. $\boldsymbol{D}$, Low-power image of BrdU + nuclei (green) and BLBP+ staining surrounding the central canal just rostral to the site of contusion. Some BrdU + nuclei are colocalized with BLBP + cells (yellow arrowheads), whereas some others are not (white arrows). $\boldsymbol{E}$, High-magnification confocal image of BrdU + (green) astrocytes (BLBP, red) with axons (NF, blue) growing alongside them (white arrows). $F$, Confocal z-stack and projection images (right and bottom) of a BrdU + I BLBP + cell in white matter near the lesion border. $\mathbf{G}, \mathbf{G}^{\prime \prime}$, TGF $\alpha$-AAV increases proliferation of cells at the lesion border. $\mathbf{G}$, Low-power wide-field image series of BLBP immunostaining at $200 \mu \mathrm{m}$ intervals spanning the lesion in a TGF $\alpha$-AAV-treated specimen. Counting frames (white boxes) are shown at the rostral and caudal borders. $G^{\prime}$, Enlargement of confocal image showing $\mathrm{BrdU}+$ nuclei and BLBP + staining with a counting frame from a representative section. $G^{\prime \prime}$, More BrdU + nuclei were found at the lesion borders in TGF $\alpha$-AAV-treated mice than PBS- or eAAV-treated mice. $\boldsymbol{H}$, High-power confocal image and projection of $\mathrm{BrdU}+/ \mathrm{BLBP}+$ cell intertwined with NF+ axons within the caudal lesion border. $p<0.01$, two-way ANOVA main-effect treatment; ${ }^{* *} p<0.01,{ }^{* * *} p<0.001$ vs PBS (posthoc comparisons); ${ }^{+} p<0.05$, versus eAAV. Scale bars: $A-A^{\prime \prime \prime}, C, D, G, 50 \mu \mathrm{m}$; $\boldsymbol{F}, 20 \mu \mathrm{m} ; \boldsymbol{B}, \boldsymbol{B}^{\prime}, \boldsymbol{E}, \boldsymbol{H}, 10 \mu \mathrm{m}$.

onal growth while maintaining the neuroprotective functions of these cells.

The first goal of this study was to identify the cellular targets of TGF $\alpha$ activation early after injury. EGFR immunoreactivity is first detected in astrocytes at about $16 \mathrm{~d}$ postnatal, and then it decreases and is expressed in very low levels in neurons throughout the brain (Gómez-Pinilla et al., 1988). Previous experiments have shown that EGFR expression increases after SCI (Aimone et al., 2004; Erschbamer et al., 2007; White et al., 2008), but we now show that expression shifts dramatically after contusion from low 
A
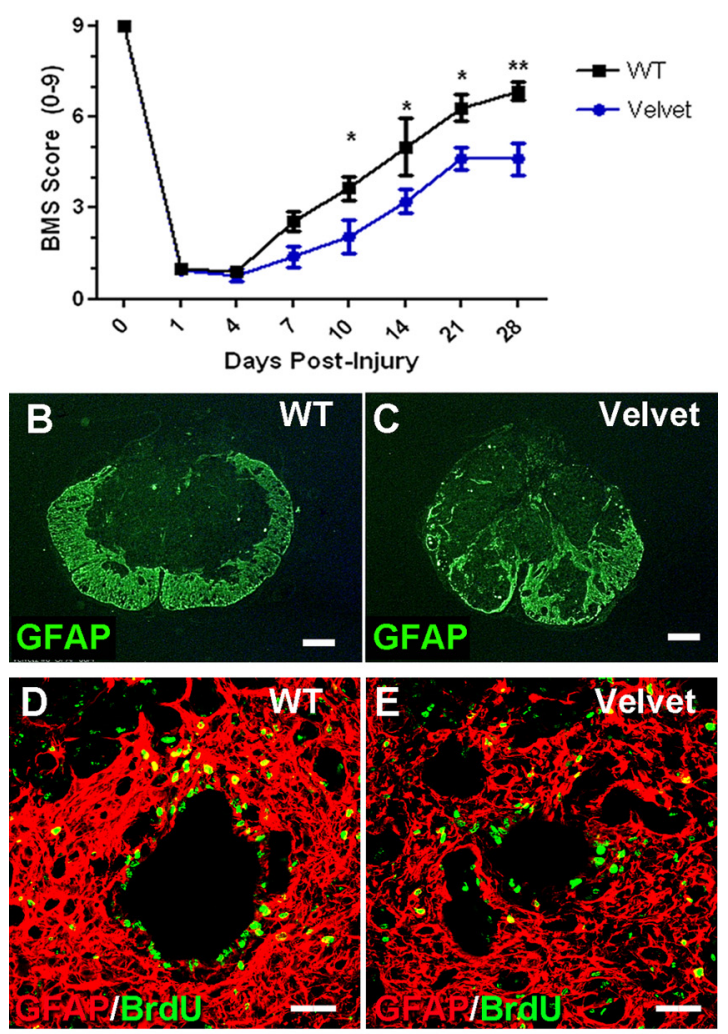

$\mathbf{F}$

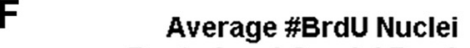
Rostral and Caudal Borders

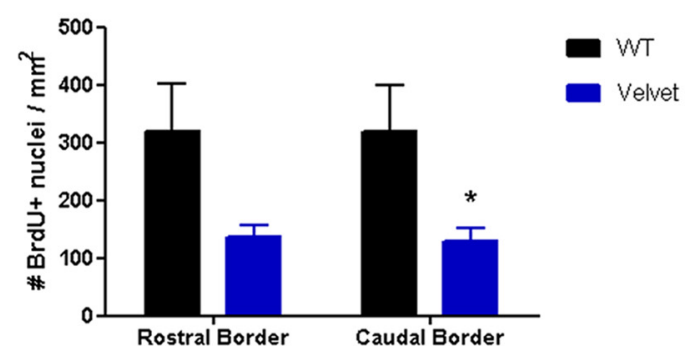

Figure 9. Mice with dominant Velvet gene show impaired locomotor recovery and enlarged GFAP-negative area at the lesion epicenter after $\mathrm{SCl}$. A, Locomotor recovery is impaired in Velvet mice compared with WT littermates. Two-way ANOVA revealed main effects of time $(p<0.001)$, treatment $(p<0.01)$, and interaction $(p<0.01)$; ${ }^{*} p<0.05,{ }^{* *} p<0.01$ (posthoc). $\boldsymbol{B}, \boldsymbol{C}$, Images of GFAP immunoreactivity at the lesion epicenter of a WT $(\boldsymbol{C})$ and Velvet $(\boldsymbol{D})$ specimen showing abnormal scar formation in the mutant mouse. $\boldsymbol{D}, \boldsymbol{E}, \mathrm{BrdU}+$ nuclei (green) are found throughout the GFAP+ stained region at the lesion borders. $\boldsymbol{F}$, Two-way ANOVA revealed a significant main effect of genotype on the number of $\mathrm{BrdU}+$ nucleiper sample region. ${ }^{*} p<0.05$, by post hoc corrected Bonferroni's test. Scale bars: $\boldsymbol{B}, \boldsymbol{C}, 100 \mu \mathrm{m} ; \boldsymbol{D}, \boldsymbol{E}, 40 \mu \mathrm{m}$.

levels in neurons and axon profiles to high levels in both astrocytes and, importantly, putative astrocyte precursors surrounding the central canal, which may represent a pro-reparative cell target (Kojima and Tator, 2002; Meletis et al., 2008). Thus, the EGFR is appropriately expressed early after injury at high levels in those cells targeted for modifying the astrocyte response.

We then performed in vitro studies to determine the direct effects of the EGFR ligand TGF $\alpha$ on the targeted populations obtained specifically from the injured adult spinal cord. Whereas prior work had shown that EGF and TGF $\alpha$ stimulate proliferation of forebrain progenitor cells (Anchan et al., 1991; Reynolds and Weiss, 1992) and transform primary cortical astrocyte cultures (Sharif et al., 2006, 2007), it was not clear whether these effects were attributable to actions on the progenitors or whether astrocytes derived from adult spinal cord would be able to respond similarly. TGF $\alpha$ was a potent and direct mediator of robust proliferation and migration of progenitors but did not induce migration of mature astrocytes. Importantly, astrocytes exposed to TGF $\alpha$ were dramatically changed over a few days to provide a growth-supportive substrate for DRG neurons. Thus, EGFR activation can induce characteristics in the targeted populations that are necessary for endogenous cellular bridge formation across a wound site.

As anticipated from the in vitro studies, we then found that after overexpression in vivo, TGF $\alpha$ increased cell proliferation around the borders of the contusion site and reduced the volume of the nonpermissive, GFAP-free lesion core. NF-positive axons were indeed observed in association with the astrocyte-rich regions at the borders, and more axons were able to penetrate the rostral end of the lesion. Although the effects were admittedly less robust than we had wanted, they indicate clearly that the adult astrocytes are amenable to manipulation in vivo and that activated astrocytes can support growing axons. These findings provide new light to a continuing controversy regarding the role of EGFR signaling on axonal regeneration. In prior work, EGFR activation has been shown to inhibit growth in the presence of myelin or chondroitin sulfate proteoglycans (Koprivica et al., 2005; Ahmed et al., 2009) and fibrinogen (Schachtrup et al., 2007), and blocking EGFR activation can promote growth on these substrates. However, after injury, the EGFRs are expressed primarily on astrocytes and not on axons, and EGFR inhibition alone does not enhance axon growth on permissive substrates (Koprivica et al., 2005). In fact, we demonstrate here that TGF $\alpha$ does not inhibit growth of DRG axons plated on laminin. It has been shown that growth-promoting effects of EGFR inhibitors in some models may be mediated by off-target actions of these compounds on surrounding glial cells that then promote growth cone extension (Ahmed et al., 2009; Douglas et al., 2009). At the site of traumatic injury, growing axons that come from the CNS encounter a basal lamina and additional inhibitory cues at the astrocyte border. Thus, stimulating astrocyte migration can facilitate growth into and potentially beyond the injury site.

The present study also raises the interesting prospect that in addition to contributing to astrocyte proliferation and migration, intrinsic EGFR activation also plays an essential role in a neuroprotective effect of EGFR-expressing cells after injury. Although we cannot rule out the possibility that the effects of the EGFR mutation in Velvet mice were caused by other EGFR-expressing cells, we observed that the astrocyte border surrounding a spinal contusion injury was disrupted and the lesions were larger in the absence of signaling by this receptor. The results are consistent with those of Faulkner et al. (2004), who demonstrated proliferating astrocytes are essential to prevent expansion of secondary inflammation after spinal cord injury. In contrast, Erschbamer et al. (2007) reported that prolonged intrathecal administration of an EGFR inhibitor can improve behavioral recovery after contusion SCI in the rat, and a recent report by Li et al. (2011) indicated that a similar chronic infusion of AG1478 attenuates glial reactivity and improves function in a similar model. The contrasting results suggest that the effects of EGFR activation and inhibition are highly dependent on the context of other cellular signals. Liu and Neufeld (2007) argued that a developmental switch dictates the beneficial versus detrimental response of astrocytes to EGFR activation. Alternatively, the effects of EGFR activation after contusion may depend on the timing of exposure and presence of competing signals. Very early after injury, EGFR activation may be essential to drive endogenous protective mechanisms. Over 
time, however, the increased expression of inflammatory cytokines and additional growth factors, including EGFR ligands, will affect downstream signals and drive astrocytes to contribute to a fully mature scar with prominent growth-inhibitory characteristics (Levison et al., 1996; Rabchevsky et al., 1998; Zai et al., 2005; Ishii et al., 2006; Pineau and Lacroix, 2007; Santos-Silva et al., 2007). Thus, it is critical to develop a better understanding of the timing of activation of the EGFR signaling pathways in the context of the changing microenvironment to induce an endogenous glial response that will support more extensive regeneration and improve functional outcome.

\section{Conclusions}

Astrocytes are heterogeneous cells that are exquisitely responsive to local cues and represent promising candidates as therapeutic targets to alter the growth-inhibitory characteristics of the lesion border. Using a TGF $\alpha$-AAV to induce intraparenchymal activation of the EGFR, we have successfully manipulated astrocytes and astrocyte precursors to encourage a modest pro-reparative and growthsupportive phenotype. Notably, although we saw no evidence of tumor formation in any treated specimens, direct application of TGF $\alpha$ to the spinal cord is not likely to be a feasible long-term approach because of potential oncogenic characteristics of uncontrolled activation of these cellular pathways (for review, see Ronellenfitsch et al., 2010). In addition, it is important to recognize that even after formation of a permissive growth-supportive substrate, regeneration in the adult CNS will still be limited by the poor intrinsic growth capacity of injured adult CNS axons. However, strategies directed at modifying the astrocyte response early after injury represent a first step toward tissue repair after SCI.

\section{References}

Ahmed Z, Jacques SJ, Berry M, Logan A (2009) Epidermal growth factor receptor inhibitors promote CNS axon growth through off-target effects on glia. Neurobiol Dis 36:142-150.

Aimone JB, Leasure JL, Perreau VM, Thallmair M (2004) Spatial and temporal gene expression profiling of the contused rat spinal cord. Exp Neurol 189:204-221.

Anchan RM, Reh TA, Angello J, Balliet A, Walker M (1991) EGF and TGFalpha stimulate retinal neuroepithelial cell proliferation in vitro. Neuron 6:923-936.

Barry D, McDermott K (2005) Differentiation of radial glia from radial precursor cells and transformation into astrocytes in the developing rat spinal cord. Glia 50:187-197.

Basso DM, Fisher LC, Anderson AJ, Jakeman LB, McTigue DM, Popovich PG (2006) Basso Mouse Scale for locomotion detects differences in recovery after spinal cord injury in five common mouse strains. J Neurotrauma 23:635-659.

Blits B, Derks S, Twisk J, Ehlert E, Prins J, Verhaagen J (2010) Adenoassociated viral vector (AAV)-mediated gene transfer in the red nucleus of the adult rat brain: comparative analysis of the transduction properties of seven AAV serotypes and lentiviral vectors. J Neurosci Methods 185:257-263.

Brunet JF, Grollimund L, Chatton JY, Lengacher S, Magistretti PJ, Villemure JG, Pellerin L (2004) Early acquisition of typical metabolic features upon differentiation of mouse neural stem cells into astrocytes. Glia $46: 8-17$.

Camand E, Morel MP, Faissner A, Sotelo C, Dusart I (2004) Long-term changes in the molecular composition of the glial scar and progressive increase of serotoninergic fibre sprouting after hemisection of the mouse spinal cord. Eur J Neurosci 20:1161-1176.

Chernoff EA, Stocum DL, Nye HL, Cameron JA (2003) Urodele spinal cord regeneration and related processes. Dev Dyn 226:295-307.

Davies JE, Huang C, Proschel C, Noble M, Mayer-Proschel M, Davies SJ (2006) Astrocytes derived from glial-restricted precursors promote spinal cord repair. J Biol 5:7.

Davies JE, Pröschel C, Zhang N, Noble M, Mayer-Pröschel M, Davies SJ (2008) Transplanted astrocytes derived from BMP- or CNTF-treated glial-restricted precursors have opposite effects on recovery and allodynia after spinal cord injury. J Biol 7:24.

Deng LX, Hu J, Liu N, Wang X, Smith GM, Wen X, Xu XM (2011) GDNF modifies reactive astrogliosis allowing robust axonal regeneration through Schwann cell-seeded guidance channels after spinal cord injury. Exp Neurol 229:238-250.

Douglas MR, Morrison KC, Jacques SJ, Leadbeater WE, Gonzalez AM, Berry M, Logan A, Ahmed Z (2009) Off-target effects of epidermal growth factor receptor antagonists mediate retinal ganglion cell disinhibited axon growth. Brain 2009 132:3102-3121.

Du X, Tabeta K, Hoebe K, Liu H, Mann N, Mudd S, Crozat K, Sovath S, Gong X, Beutler B (2004) Velvet, a dominant Egfr mutation that causes wavy hair and defective eyelid development in mice. Genetics 166:331-340.

Erdfelder E, Faul F, Buchner A (1996) GPOWER: a general power analysis program. Behav Res Methods Instrum Comput 28:1-11.

Erschbamer M, Pernold K, Olson L (2007) Inhibiting epidermal growth factor receptor improves structural, locomotor, sensory, and bladder recovery from experimental spinal cord injury. J Neurosci 27:6428-6435.

Faber-Elman A, Solomon A, Abraham JA, Marikovsky M, Schwartz M (1996) Involvement of wound-associated factors in rat brain astrocyte migratory response to axonal injury: in vitro simulation. J Clin Invest 97:162-171.

Faulkner JR, Herrmann JE, Woo MJ, Tansey KE, Doan NB, Sofroniew MV (2004) Reactive astrocytes protect tissue and preserve function after spinal cord injury. J Neurosci 24:2143-2155.

Filous AR, Miller JH, Coulson-Thomas YM, Horn KP, Alilain WJ, Silver J (2010) Immature astrocytes promote CNS axonal regeneration when combined with chondroitinase ABC. Dev Neurobiol 70:826-841.

Fitch MT, Doller C, Combs CK, Landreth GE, Silver J (1999) Cellular and molecular mechanisms of glial scarring and progressive cavitation: in vivo and in vitro analysis of inflammation-induced secondary injury after CNS trauma. J Neurosci 19:8182-8198.

Frisen J, Haegerstrand A, Risling M, Fried K, Johansson CB, Hammarberg H, Elde R, Hokfelt T, Cullheim S (1995) Spinal axons in central nervous system scar tissue are closely related to laminin-immunoreactive astrocytes. Neuroscience 65:293-304.

Fry EJ, Stolp HB, Lane MA, Dziegielewska KM, Saunders NR (2003) Regeneration of supraspinal axons after complete transection of the thoracic spinal cord in neonatal opossums (Monodelphis domestica). J Comp Neurol 466:422-444.

Gensel JC, Nakamura S, Guan Z, van Rooijen N, Ankeny DP, Popovich PG (2009) Macrophages promote axon regeneration with concurrent neurotoxicity. J Neurosci 29:3956-3968.

Gensel JC, Schonberg DL, Alexander JK, McTigue DM, Popovich PG (2010) Semi-automated Sholl analysis for quantifying changes in growth and differentiation of neurons and glia. J Neurosci Methods 190:71-79.

Gómez-Pinilla F, Knauer DJ, Nieto-Sampedro M (1988) Epidermal growth factor receptor immunoreactivity in rat brain. Development and cellular localization. Brain Res 438:385-390.

Hasegawa K, Chang YW, Li H, Berlin Y, Ikeda O, Kane-Goldsmith N, Grumet M (2005) Embryonic radial glia bridge spinal cord lesions and promote functional recovery following spinal cord injury. Exp Neurol 193:394-410.

Herrmann JE, Imura T, Song B, Qi J, Ao Y, Nguyen TK, Korsak RA, Takeda K, Akira S, Sofroniew MV (2008) STAT3 is a critical regulator of astrogliosis and scar formation after spinal cord injury. J Neurosci 28:7231-7243.

Houle JD, Jin Y (2001) Chronically injured supraspinal neurons exhibit only modest axonal dieback in response to a cervical hemisection lesion. Exp Neurol 169:208-217.

Howard CV, Reed MA (1998) Unbiased stereology: three-dimensional measurements in microscopy. New York: Bios Scientific Publishers Limited.

Inman DM, Steward O (2003) Ascending sensory, but not other long-tract axons, regenerate into the connective tissue matrix that forms at the site of a spinal cord injury in mice. J Comp Neurol 462:431-449.

Ishii K, Nakamura M, Dai H, Finn TP, Okano H, Toyama Y, Bregman BS (2006) Neutralization of ciliary neurotrophic factor reduces astrocyte production from transplanted neural stem cells and promotes regeneration of corticospinal tract fibers in spinal cord injury. J Neurosci Res $84: 1669-1681$.

Jakeman LB (2011) Assessment of lesion and tissue sparing volumes following spinal cord injury. In: Animal models of acute neurological injuries, 
Vol 2, Chap 84 (Chen J, Xu XM, Xu ZC, Zhang JH, eds). Totowa, NJ: Humana.

Jakeman LB, Guan Z, Wei P, Ponnappan R, Dzwonczyk R, Popovich PG, Stokes BT. (2000) Traumatic spinal cord injury produced by controlled contusion in mouse. J Neurotrauma 17:299-319.

Jin Y, Neuhuber B, Singh A, Bouyer J, Lepore A, Bonner J, Himes T, Campanelli JT, Fischer I (2011) Transplantation of human glial restricted progenitors and derived astrocytes into a contusion model of spinal cord injury. J Neurotrauma 28:579-594.

Kigerl KA, Lai W, Rivest S, Hart RP, Satoskar AR, Popovich PG (2007) Tolllike receptor (TLR)-2 and TLR-4 regulate inflammation, gliosis, and myelin sparing after spinal cord injury. J Neurochem 102:37-50.

King VR, Phillips JB, Hunt-Grubbe H, Brown R, Priestley JV (2006) Characterization of non-neuronal elements within fibronectin mats implanted into the damaged adult rat spinal cord. Biomaterials 7:485-496.

Koerber JT, Klimczak R, Jang JH, Dalkara D, Flannery JG, Schaffer DV (2009) Molecular evolution of adeno-associated virus for enhanced glial gene delivery. Mol Ther 17:2088-2095.

Kojima A, Tator CH (2002) Intrathecal administration of epidermal growth factor and fibroblast growth factor 2 promotes ependymal proliferation and functional recovery after spinal cord injury in adult rats. J Neurotrauma 19:223-238.

Koprivica V, Cho KS, Park JB, Yiu G, Atwal J, Gore B, Kim JA, Lin E, TessierLavigne M, Chen DF, He Z (2005) EGFR activation mediates inhibition of axon regeneration by myelin and chondroitin sulfate proteoglycans. Science 310:106-110.

Kota J, Handy CR, Haidet AM, Montgomery CL, Eagle A, Rodino-Klapac LR, Tucker D, Shilling CJ, Therlfall WR, Walker CM, Weisbrode SE, Janssen PM, Clark KR, Sahenk Z, Mendell JR, Kaspar BK (2009) Follistatin gene delivery enhances muscle growth and strength in nonhuman primates. Sci Transl Med 1:6ra15.

Lane MA, Truettner JS, Brunschwig JP, Gomez A, Bunge MB, Dietrich WD, Dziegielewska KM, Ek CJ, Vandeberg JL, Saunders NR (2007) Agerelated differences in the local cellular and molecular responses to injury in developing spinal cord of the opossum, Monodelphis domestica. Eur J Neurosci 25:1725-1742.

Lee JK, Chow R, Xie F, Chow SY, Tolentino KE, Zheng B (2010) Combined genetic attenuation of myelin and semaphorin-mediated growth inhibition is insufficient to promote serotonergic axon regeneration. J Neurosci 30:10899-10904.

Levison SW, Ducceschi MH, Young GM, Wood TL (1996) Acute exposure to CNTF in vivo induces multiple components of reactive gliosis. Exp Neurol 141:256-268.

Li ZW, Tang RH, Zhang JP, Tang ZP, Qu WS, Zhu WH, Li JJ, Xie MJ, Tian DS, Wang W (2011) Inhibiting epidermal growth factor receptor attenuates reactive astrogliosis and improves functional outcome after spinal cord injury in rats. Neurochem Int. Advance online publication. doi:10.1016/ j.neuint.2011.03.007.

Liu B, Neufeld AH (2007) Activation of epidermal growth factor receptors in astrocytes: from development to neural injury J Neurosci Res 85:3523-3529.

Liu K, Lu Y, Lee JK, Samara R, Willenberg R, Sears-Kraxberger I, Tedeschi A, Park KK, Jin D, Cai B, Xu B, Connolly L, Steward O, Zheng B, He Z (2010) PTEN deletion enhances the regenerative ability of adult corticospinal neurons. Nat Neurosci 13:1075-1081.

Liuzzi FJ, Lasek RJ (1987) Astrocytes block axonal regeneration in mammals by activating the physiological stop pathway. Science 237:642-645.

Ma M, Wei P, Wei T, Ransohoff RM, Jakeman LB (2004) Enhanced axonal growth into a spinal cord contusion injury site in a strain of mouse (129X1/SvJ) with a diminished inflammatory response. J Comp Neurol 474:469-486.

McDermott KW, Barry DS, McMahon SS (2005) Role of radial glia in cytogenesis, patterning and boundary formation in the developing spinal cord. J Anat 207:241-250.

Meletis K, Barnabe-Heider F, Carlen M, Evergren E, Tomilin N, Shupliakov O, Frisen J (2008) Spinal cord injury reveals multilineage differentiation of ependymal cells. PLoS Biol 6:e182.

Okada S, Nakamura M, Katoh H, Miyao T, Shimazaki T, Ishii K, Yamane J, Yoshimura A, Iwamoto Y, Toyama Y, Okano H (2006) Conditional ablation of Stat 3 or Socs 3 discloses a dual role for reactive astrocytes after spinal cord injury. Nat Med 12:829-834.
Pekny M, Johansson CB, Eliasson C, Stakeberg J, Wallen A, Perlmann T, Lendahl U, Betsholtz C, Berthold CH, Frisen J (1999) Abnormal reaction to central nervous system injury in mice lacking glial fibrillary acidic protein and vimentin. J Cell Biol 145:503-514.

Pineau I, Lacroix S (2007) Proinflammatory cytokine synthesis in the injured mouse spinal cord: multiphasic expression pattern and identification of the cell types involved. J Comp Neurol 500:267-285.

Rabchevsky AG, Weinitz JM, Coulpier M, Fages C, Tinel M, Junier MP (1998) A role for transforming growth factor alpha as an inducer of astrogliosis. J Neurosci 18:10541-10552.

Rakic P (1971) Guidance of neurons migrating to the fetal monkey neocortex. Brain Res 33:471-476.

Ray J, Gage FH (2006) Differential properties of adult rat and mouse brainderived neural stem/progenitor cells. Mol Cell Neurosci 31:560-573.

Rehermann MI, Marichal N, Russo RE, Trujillo-Cenoz O (2009) Neural reconnection in the transected spinal cord of the freshwater turtle Trachemys dorbignyi. J Comp Neurol 515:197-214.

Reier PJ, Stensaas LJ, Guth L (1983) The astrocytic scar as an impediment to regeneration in the nervous system. In: Spinal cord reconstruction (Kao CC, Bunge RP, Reier PJ, eds), pp163-195. New York: Raven.

Remboutsika E, Elkouris M, Iulianella A, Andoniadou CL, Poulou M, Mitsiadis TA, Trainor PA, Lovell-Badge R (2011) Flexibility of neural stem cells. Front Physiol 2:16-26.

Reynolds BA, Weiss S (1992) Generation of neurons and astrocytes from isolated cells of the adult mammalian central nervous system. Science 255:1707-1710

Ronellenfitsch MW, Steinbach JP, Wick W (2010) Epidermal growth factor receptor and mammalian target of rapamycin as therapeutic targets in malignant glioma: current clinical status and perspectives. Target Oncol 5:183-191.

Rudge JS, Silver J (1990) Inhibition of neurite outgrowth on astroglial scars in vitro. J Neurosci 10:3594-3603.

Santos-Silva A, Fairless R, Frame MC, Montague P, Smith GM, Toft A, Riddell JS, Barnett SC (2007) FGF/heparin differentially regulates Schwann cell and olfactory ensheathing cell interactions with astrocytes: a role in astrocytosis. J Neurosci 27:7154-7167.

Schachtrup C, Lu P, Jones LL, Lee JK, Lu J, Sachs BD, Zheng B, Akassoglou K (2007) Fibrinogen inhibits neurite outgrowth via beta 3 integrinmediated phosphorylation of the EGF receptor. Proc Natl Acad Sci U S A 104:11814-11819.

Scheff SW, Rabchevsky AG, Fugaccia I, Main JA, Lumpp JE, Jr (2003) Experimental modeling of spinal cord injury: characterization of a forcedefined injury device. J Neurotrauma 20:179-193.

Sharif A, Prevot V, Renault-Mihara F, Allet C, Studler JM, Canton B, Chneiweiss H, Junier MP (2006) Transforming growth factor alpha acts as a gliatrophin for mouse and human astrocytes. Oncogene 25:4076-4085.

Sharif A, Legendre P, Prevot V, Allet C, Romao L, Studler JM, Chneiweiss H, Junier MP (2007) Transforming growth factor alpha promotes sequential conversion of mature astrocytes into neural progenitors and stem cells. Oncogene 26:2695-2706.

Skene JH, Willard M (1981) Changes in axonally transported proteins during axon regeneration in toad retinal ganglion cells. J Cell Biol 89:86-95.

Vaccarino FM, Fagel DM, Ganat Y, Maragnoli ME, Ment LR, Ohkubo Y, Schwartz ML, Silbereis J, Smith KM (2007) Astroglial cells in development, regeneration, and repair. Neuroscientist 13:173-185.

White RE, Jakeman LB (2008) Don't fence me in: harnessing the beneficial roles of astrocytes for spinal cord repair. Restor Neurol Neurosci 26:197-214.

White RE, Yin FQ, Jakeman LB (2008) TGF-alpha increases astrocyte invasion and promotes axonal growth into the lesion following spinal cord injury in mice. Exp Neurol 214:10-24.

White RE, McTigue DM, Jakeman LB (2010) Regional heterogeneity in astrocyte responses following contusive spinal cord injury in mice. J Comp Neurol 518:1370-1390.

Williams RW, Rakic P (1988) Three-dimensional counting: an accurate and direct method to estimate numbers of cells in sectioned material. J Comp Neurol 278:344-352.

Zai LJ, Yoo S, Wrathall JR (2005) Increased growth factor expression and cell proliferation after contusive spinal cord injury. Brain Res 1052:147155 . 